\title{
The Photochemistry of Gas Molecules in Earth's Atmosphere Determines the Structure of the Atmosphere and the Average Temperature at Earth's Surface
}

\author{
Peter Langdon Ward \\ United States Geological Survey Retired, Science Is Never Settled, Inc., Jackson, Wyoming, USA
}

\section{Email address:}

peward@wyoming.com

\section{To cite this article:}

Peter Langdon Ward. The Photochemistry of Gas Molecules in Earth's Atmosphere Determines the Structure of the Atmosphere and the Average Temperature at Earth's Surface. American Journal of Physical Chemistry. Vol. 9, No. 3, 2020, pp. 62-85.

doi: 10.11648/j.ajpc.20200903.13

Received: July 23, 2020; Accepted: August 3, 2020; Published: August 19, 2020

\begin{abstract}
A molecule of oxygen absorbing solar ultraviolet-C radiation is photo-dissociated into two atoms of oxygen that fly apart at high velocity, converting kinetic energy of oscillation of the molecular bond directly and completely into kinetic energy of linear motion of the oxygen atoms. This increases air temperature. Two oxygen atoms can then collide forming a new oxygen molecule that can then be dissociated again as long as sufficient ultraviolet-C radiation exists. This continual dissociation of oxygen molecules is the primary reason for the stratopause being 30-40 degrees warmer than the tropopause and for all ultraviolet-C radiation being absorbed before reaching the lower stratosphere. Furthermore, an oxygen molecule and an oxygen atom can collide to form a molecule of ozone, which is photo-dissociated by solar ultraviolet-B radiation. Normally, 97-99 percent of ultraviolet-B radiation is absorbed in the ozone layer, warming the lower stratosphere. By 1970, however, humans manufacturing chlorofluorocarbon gases caused up to $70 \%$ depletion of ozone, cooling the ozone layer and allowing more ultraviolet-B to reach Earth where it photo-dissociates ground-level ozone pollution, raising air temperatures, especially in the most polluted areas. Ultraviolet-B also penetrates oceans tens of meters, efficiently raising ocean heat content. Earth's surface warmed $0.6^{\circ} \mathrm{C}$ from 1970 to 1998 with warming twice as great in the northern hemisphere containing $90 \%$ of global population. In 2014, Bárðarbunga volcano in central Iceland extruded $85 \mathrm{~km}^{2}$ of basaltic lavas in six months, depleting the ozone layer and warming Earth another $0.3^{\circ} \mathrm{C}$ by 2016 . Throughout Earth history, basaltic lava flows covering areas of up to millions of square kilometers are contemporaneous with sudden global warming - the larger the lava flow, the greater the warming. Large explosive volcanic eruptions, on the other hand, typically form aerosols in the lower stratosphere that spread throughout the world, reflecting and scattering sunlight, cooling Earth approximately $0.5^{\circ} \mathrm{C}$ for two to four years. Computer modelling shows the effects of this global cooling can still be observed in ocean temperatures a century later. Several large explosive volcanic eruptions per century, continuing for millennia, cool oceans incrementally down into ice-age conditions. Detailed measurements of air temperatures in ice cores at Summit Greenland over the past 122,000 years show that the footprints of climate change are sudden warming within years, followed by slow, incremental cooling over millennia, in highly erratic sequences averaging only a few thousand years in length. Ozone depletion and aerosols are particularly effective because they occur worldwide.
\end{abstract}

Keywords: Dissociation, Thermal Energy, Photochemistry, Ozone Depletion, Aerosols, Explosive Volcanism, Effusive Volcanism, Basalt

\section{Introduction}

Photochemistry is the study of the chemical and physical processes occurring when solid matter, liquids, gases, or plasmas absorb thermal energy in the form of electromagnetic radiation. Earth is showered with solar electromagnetic radiation consisting primarily of infrared frequencies that provide warmth, visible frequencies that power photosynthesis, enable sight, and heat Earth's surface, ultraviolet-A frequencies that heat Earth's surface, ultraviolet-B frequencies that heat the stratospheric ozone layer, ground-level ozone pollution, and Earth's surface, 
ultraviolet-C frequencies that heat the stratosphere and mesosphere, and extreme ultraviolet, $\mathrm{X}$-ray, and gamma ray frequencies that ionize and heat the ionosphere and thermosphere.

Humans thrive on Earth only because essentially all high-energy, DNA-damaging, solar radiation, including ultraviolet-C, extreme ultraviolet, X-ray, and gamma ray frequencies are absorbed in the stratosphere, mesosphere, and the upper atmosphere. The true Goldilocks balance, however, is centered on how much solar ultraviolet-B radiation reaches Earth's surface. The skin of humans must absorb just enough ultraviolet-B to manufacture sufficient vitamin-D, crucial for healthy bone growth and for healthy immune systems. Just enough ultraviolet-B is also required for healthy plant development [1]. But too much ultraviolet-B causes photodegradation, sunburn, premature aging of skin, skin cancer, cataracts, and disruption of DNA, killing or inactivating microorganisms and causing mutations in plants and animals. Too much ultraviolet-B inhibits animal and plant growth [2]. And too much ultraviolet-B reaching Earth's surface, as discussed in this paper, causes heating of Earth's surface above the Goldilocks ideal temperature that life on Earth has adapted to.

Human skin evolved to absorb just enough ultraviolet-B radiation long before clothes were available. The dosage of ultraviolet-B radiation reaching human skin is greatest in the tropics, least around the poles, and varies with climate change. Around 1.2 million years ago, in response to climate change killing trees, hominins moved out of tropical rainforests into sunny savannas where they lost body hair, evolved more efficient perspiration, and evolved short, curly, Afro-textured hair to protect the thermosensitive brain from bright sunshine $[3,4]$. The loss of body hair led to heritable increases in melanin, a pigment that blackens the skin and darkens the eyes of people living in intense sunlight in equatorial regions. Our species, Homo sapiens, evolved in Africa and was originally dark skinned. As humans migrated out of equatorial Africa to higher latitudes, where sunshine is less intense, they evolved over hundreds of generations lower levels of melanin, leading to lighter skin and lighter eye color so that they could absorb adequate ultraviolet-B radiation to have healthy levels of vitamin D. Humans evolved straighter hair that provided increased warmth. Eskimos in the Arctic kept dark skin perhaps because of nearly 24-hour sunlight half the year and because they absorb large amounts of vitamin D from their diet primarily of fish, seals and other animals [5].

Thus, the existence, health, and even skin color of humans living on Earth is determined by having just the right Goldilocks balance between how much solar ultraviolet-B radiation is absorbed by the ozone layer versus how much reaches Earth's surface. The fact that 97 to 99 percent of ultraviolet-B radiation is absorbed within the ozone layer, protecting life on Earth from this generally harmful radiation, has been known and understood for a long time [6]. In 1974, Molina and Rowland discovered that manufactured chlorofluorocarbon gases (CFCs) were depleting the ozone layer [7]. In 1985, Farman, Gardiner, and Shanklin [8] discovered the Antarctic ozone hole showing that ozone depletion was much more significant than had been realized. In 1995, Molina, Rowland, and Crutzen shared the Nobel Prize in Chemistry for their work "concerning the formation and decomposition of ozone" [9].

What has not been understood, and is the primary subject of this paper, is that this Goldilocks balance of solar ultraviolet-B radiation also determines the average temperature of air at Earth's surface. Ultraviolet-B radiation, with frequencies around 1176 trillion cycles per second, has enough kinetic energy of oscillation, around 4.86 electronvolts, to photo-dissociate ozone $\left(\mathrm{O}_{3}\right)$. When a gas molecule is dissociated, one of the bonds holding the molecule together is broken, causing the molecular pieces to fly apart at high velocity. According to the kinetic theory of gases, air temperature is proportional to the average kinetic energy of linear motion of all atoms and molecules making up the gas. The average kinetic energy of linear motion is proportional to the average velocity of linear motion squared.

As discussed below, radiation is the result of oscillation of all the bonds holding matter together. Photo-dissociation converts the kinetic energy of oscillation of a bond directly and completely into kinetic energy of linear motion, which is proportional to temperature. Absorption of ultraviolet-B radiation, dissociating ozone, heats the ozone layer. When more ultraviolet-B radiation than usual reaches Earth's surface, it photo-dissociates ground-level ozone pollution, warming air. Ultraviolet-B also penetrates oceans tens of meters, directly causing substantial increases in ocean heat content. Ultraviolet-B has the greatest effect on global temperatures at Earth's surface because it is the most energetic, "hottest" solar radiation with the greatest temperature difference from Earth. Flux of heat, as discussed below, is a function of difference in temperature.

The other photochemical process important for determining Earth's surface temperature is the reflection and scattering of sunlight by aerosols. Essentially all major explosive volcanic eruptions have been observed to form sulfuric-acid aerosols in the lower stratosphere that spread worldwide within months and last several years, reflecting and scattering sunlight, cooling Earth's surface approximately $0.5^{\circ} \mathrm{C}$ for a few years. Several large eruptions each century continuing for millennia are observed to cool oceans incrementally down into ice-age conditions.

Global warming caused by depletion of the ozone layer and global cooling caused by formation of aerosols have the dominant effects on global climate because they both modulate how much of Sun's most energetic radiation reaches Earth and they both occur worldwide, modulating all solar radiation reaching Earth. To understand why this is so important and why photo-dissociation of oxygen and ozone are so important, we need to step back and reevaluate our understanding of what thermal energy, electromagnetic radiation, temperature, and heat actually are physically and how they flow over time. We need to clear up several misunderstandings about the physics of heat. 


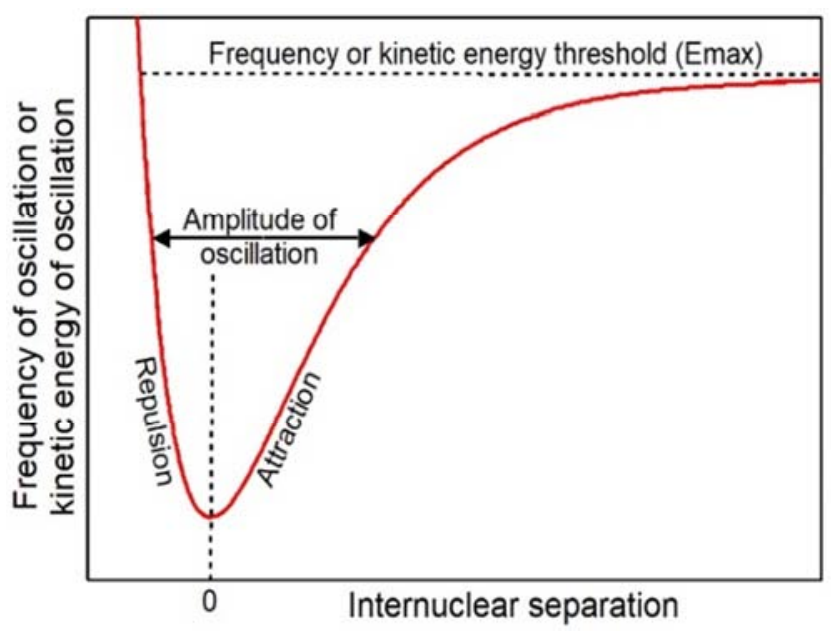

Figure 1. Oscillation of a molecular bond between forces of repulsion and forces of attraction. The molecule is dissociated when the frequency, which is also kinetic energy of oscillation, is equal to $E_{M A X}$.

In physics, the closest things to truth are direct observations of what is physically happening in Nature. The first half of this paper is based on direct observations of the flow of heat. The second half of this paper is based on direct observations of the footprints of climate change throughout the geologic record.

\section{Thermal Energy in Solid Matter Is Sub-microscopic Kinetic Energy of Oscillation}

According to Grossman [10], "by measuring temperature, we're measuring how fast the atoms in the material are moving. The higher the average velocity, of the atoms, the higher the temperature of the material."

In a gas, atoms and molecules are free to move independently in any direction until they collide with another atom, molecule, or the walls of a container. Then they typically move independently in another direction. Each atom or molecule can be thought of as "possessing" a kinetic energy of linear motion $\left(E_{\mathrm{KL}}\right)$ that is quantified as one-half its mass (m) times its velocity of linear motion (v) squared: $\mathrm{E}_{\mathrm{KL}}=1 / 2 \mathrm{mv}^{2}$. It makes no physical sense to add these kinetic energies together because each kinetic energy applies only to one discrete, individual atom or molecule. We observe a distribution of kinetic energies that we typically summarize by thinking in terms of a statistical average. We observe that temperature of a gas increases directly proportional to the statistical average of this distribution of kinetic energies. It makes no physical sense to add kinetic energies of individual molecules together. These kinetic energies are not additive - they are averative, a word I am coining to emphasize the fundamental distinction in physical reality between adding and averaging when dealing with thermal energy, heat, or temperatures. Averative will be described in more detail below.

In solid matter, physicists observe that all bonds holding matter together oscillate back and forth at trillions $\left(10^{12}\right)$ of cycles per second over amplitudes measured in picometers $\left(10^{-12}\right.$ meters). Physicists think of these oscillators as being driven by the electrodynamic forces of repulsion of like electric charges and the electrodynamic forces of attraction of unlike electric charges as approximated by the Morse potential [11] shown in Figure 1, or by the more detailed Morse/Long range potential [12]. These frequencies of oscillation are more than ten million times higher than what we humans can perceive as oscillations [13]. We perceive them as temperature of solid matter. Electrodynamic forces act like perfect springs, recoiling without energy loss from repulsion or attraction. Plus, they are frictionless, allowing these molecular-bond-scale oscillators to continue to oscillate for exceptionally long periods of time.

Each oscillator is oscillating at some frequency of oscillation with some amplitude of oscillation. Physicists observe that each oscillator on the surface of a piece of solid matter transmits into air and space its frequency of oscillation and its amplitude of oscillation in the same physical manner that a radio transmitter transmits its frequency of oscillation and its amplitude of oscillation by oscillatory motion of charge on the transmitter's antenna. The orientation of the axis of oscillation of each bond will vary, but as with a radio antenna, the resulting electromagnetic field will be greatest perpendicular to the axis of oscillation, as observed.

\section{Electromagnetic Radiation Is Physically a Very Broad Spectrum of Frequencies of Oscillation}

In this way, thermal radiation, which is defined as radiation emitted by a body of matter because of the body's temperature, is observed to consist of a very broad spectrum of frequencies of oscillation known as the electromagnetic spectrum (Figure 2) [14]. A spectrum or continuum is a continuous sequence of values in which adjacent elements are separated by differences too small to be recognized at a given scale of measurement.

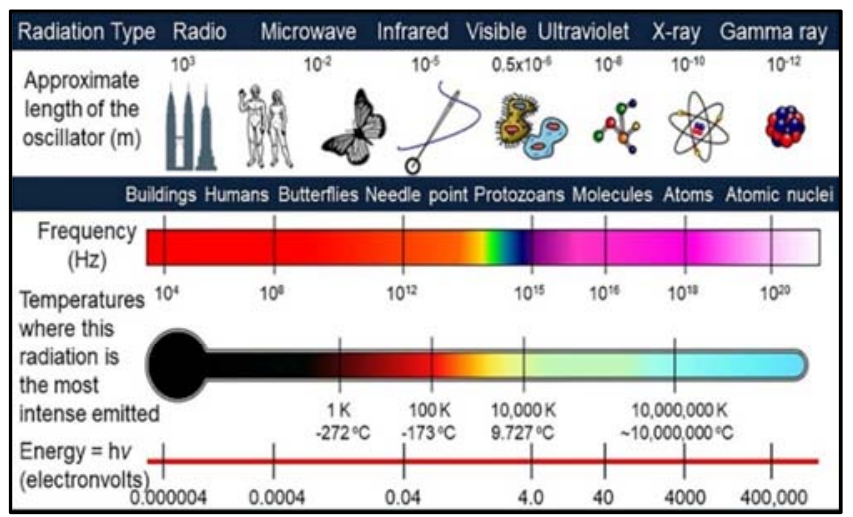

Figure 2. The electromagnetic spectrum extends from radio frequencies of cycles per second to gamma rays with frequencies greater than 300 Exahertz $\left(3 \times 10^{20}\right)$. Oscillators with a shorter length emit higher frequency, higher energy radiation associated with higher temperatures.

Today, physicists measure electromagnetic radiation with frequencies of oscillation ranging from extremely low frequency radio signals oscillating at less than one cycle per 
second to gamma rays oscillating at more than 300 exahertz $\left(3 \times 10^{20}\right.$ cycles per second). As shown in Figure 2, the shorter the length of an oscillator, the higher the frequencies of oscillation, the greater the energies of oscillation and the greater the associated temperature.

Furthermore, there can be many modes of oscillation for each oscillator and each mode can have numerous overtones or harmonics of oscillation, each with a unique frequency of oscillation. Thermal radiation from even a very small piece of solid matter is the result of simultaneous oscillation of trillions of bonds holding solid matter together. Simultaneous oscillation of a very large number of physically tiny oscillators is the primary link between the sub-microscopic world and macroscopic temperature.

Each mode of oscillation of each frictionless molecular-bond-scale oscillator can be thought of as "possessing" a kinetic energy of oscillation $\left(\mathrm{E}_{\mathrm{KO}}\right)$, which Planck [15] postulated in 1900 is equal to the frequency of oscillation (f) times a constant of proportionality (h), now known as the Planck constant. This constant is simply the kinetic energy of oscillation contained within a frequency of one cycle per second. The Planck constant, the slope of a line through the origin of a plot of kinetic energy as a function of frequency, can be estimated easily in a high-school physics laboratory using several different light-emitting diodes oscillating at different frequencies [16]. What $\mathrm{E}_{\mathrm{KO}}=\mathrm{hf}$ tells us is that frequency of oscillation (f) is physically the same thing as kinetic energy of oscillation $\left(\mathrm{E}_{\mathrm{KO}}\right)$ divided by a scaling constant $(h)$ and that kinetic energy of oscillation $\left(E_{K O}\right)$ is physically the same thing as a scaling constant (h) times frequency of oscillation (f) as calculated for all frequencies in the electromagnetic spectrum [14]. The higher the frequency of oscillation, the higher the velocity of motion of the atoms relative to each other, the higher the kinetic energy of oscillation, and the higher the related temperature (Figure 2).

It makes no physical sense to add these kinetic energies of oscillation $\left(\mathrm{E}_{\mathrm{KO}}\right)$ together because each kinetic energy applies only to one discrete, individual, molecular-bond-scale oscillator. We observe a distribution of kinetic energies that we can summarize by calculating a statistical average. We observe that temperature of solid matter increases proportional to the statistical average of this distribution of kinetic energies of oscillation. Kinetic energy of oscillation is not additive-it is averative.

\section{Temperature of Solid Matter Is the Result of This Broad Continuum of Frequencies of Oscillation}

In the late $19^{\text {th }}$ century, many physicists used a glass prism to spatially separate visible light from various sources into a spectrum or continuum of colors. They then moved various sensors through each band of color, carefully measuring changes as a function of the temperature of the source of the radiation. For infrared radiation, which does not have enough energy to penetrate glass, they utilized prisms made of halite.

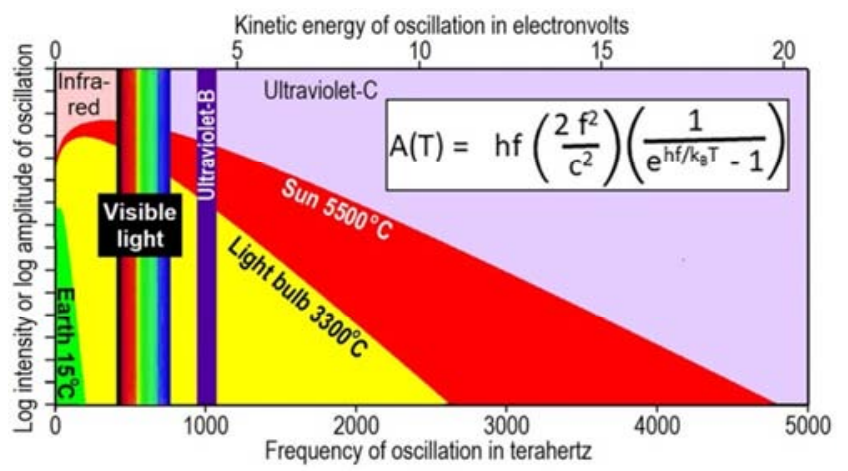

Figure 3. Planck's empirical law calculating the intensity or amplitude of oscillation at each frequency of oscillation as a function of the temperature of the radiating body. A is amplitude of oscillation, $T$ is absolute temperature, $h$ is Planck's constant, fis frequency of oscillation, $c$ is the velocity of light, and $k_{B}$ is the Boltzmann constant. A replacement for $c^{2}$ will need to be calibrated in the laboratory.

In 1900, Planck $[15,17]$ was able to devise an equation that calculates accurately the observed measurements at each frequency of oscillation as a function of the temperature of the emitting body, plotted in Figure 3 for Earth at $15^{\circ} \mathrm{C}$ (green), the filament of an incandescent light bulb at $3300^{\circ} \mathrm{C}$ (yellow and green), and Sun at $5500^{\circ} \mathrm{C}$ (red, yellow, and green). This equation, now known as Planck's empirical law, was determined by trial and error to explain extensive observations. It was not based on theory.

In the 1890 s and still today, physicists thought their sensors were measuring energy of radiation flowing per second, so Planck plotted flux of energy in watts per square meter on the $y$-axis. What is fascinating, however, is that Planck, in order to satisfy dimensional analysis for his equation, postulated that energy of radiation $\left(\mathrm{E}_{\mathrm{KO}}\right)$ is equal to the Planck constant $(\mathrm{h})$ times frequency (f), $\mathrm{E}_{\mathrm{KO}}=\mathrm{hf}$, something he called "energy elements," traditionally written $\mathrm{E}=\mathrm{h} v$, where $v$ is the Greek letter nu. In 1905, Einstein [18] called them "energy quanta", and in 1926, Lewis [19] called them "photons". But if energy $\left(E_{K O}\right)$ equals a constant (h) times frequency (f), then energy should be plotted parallel to frequency on an alternative $\mathrm{x}$-axis as shown at the top of Figure 3.

In 1900, Planck considered $\mathrm{E}_{\mathrm{KO}}=$ hf to be a "mathematical trick or convenience" and his empirical law to be a "fortunate guess" [20]. There is no evidence in the literature that he ever wondered about what energy of radiation is physically. Nevertheless, in 1918, Planck earned the Nobel Prize in Physics for "his discovery of energy quanta" [21]. In 1931, he admitted that introducing the "energy element" in 1900 was "a purely formal assumption and I really did not give it much thought except that no matter what the cost, I must bring about a positive result" [22]. In other words, Planck, a theoretical physicist, was obsessed with the mathematics rather than thinking carefully about what was actually physically happening in Nature. He did think mathematically in terms of tiny oscillators, which he called resonators, but he was confused by the widespread assumptions that energy should be plotted on the $\mathrm{y}$-axis and wavelength on the $\mathrm{x}$-axis. Wavelength and wave frequency assume the wave theory of light. What we measure in Nature is frequency of oscillation 
(Figure 3), which has nothing to do with waves.

There are two ways to look at the equation $\mathrm{E}_{\mathrm{KO}}=\mathrm{hf}$. First that $E_{K O}$ is a level of kinetic energy contained in a single frequency - the minimum level of energy ( $E_{\mathrm{MAX}}$ in Figure 1) required to break the bond of an electron in the photoelectric effect or to break a bond of a molecule causing photo-dissociation. For example, a molecule of oxygen is observed to be dissociated into two atoms of oxygen when it absorbs a frequency close to 1237 terahertz $\left(10^{12}\right.$ cycles per second), an energy close to 5.11 electronvolts [23]. In this case, $\mathrm{E}_{\mathrm{MAX}}$ can be thought of as the minimum level of energy required to cause a photochemical reaction, something Einstein called a "light quantum" [18].

The second way to look at the equation $\mathrm{E}_{\mathrm{KO}}=\mathrm{hf}$ is to recognize that frequency (f) is a very broad continuum of frequencies - the electromagnetic spectrum as shown in Figure 2 [14]. A constant times a continuum must equal a continuum. Therefore, kinetic energy $\left(\mathrm{E}_{\mathrm{KO}}\right)$ is a broad continuum of energies, the physical opposite of a "light quantum" or "photon."

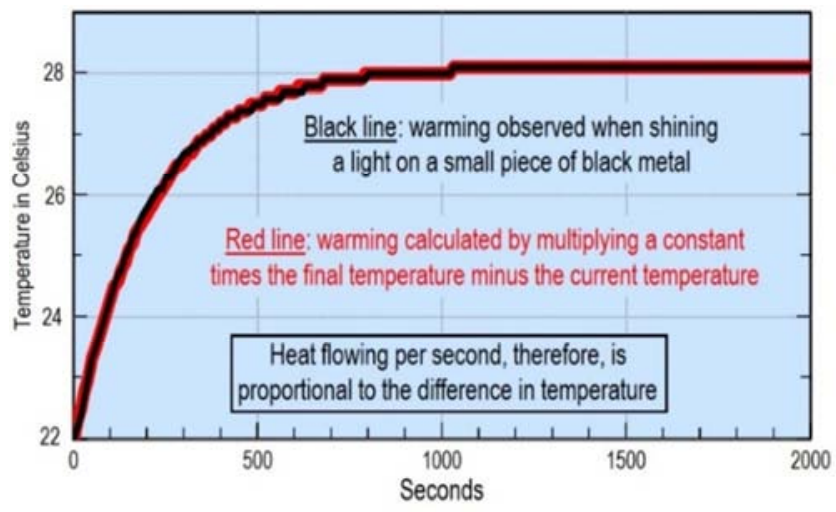

Figure 4. Heat flowing per second is proportional to the difference in temperature at that moment.

Frictionless oscillators have two primary physical properties: frequency of oscillation and amplitude of oscillation. Thus, at the sub-microscopic level, Planck's empirical law calculates amplitude of oscillation plotted on the $y$-axis as a function of frequency of oscillation or kinetic energy of oscillation plotted on the $\mathrm{x}$-axis. At the macroscopic level, our eyes perceive amplitude of oscillation as intensity or brightness. Intensity of radiant energy is currently defined as power transferred per unit area in units of watts per square meter, a flux, so that needs to be changed. Brightness is defined as an attribute of visual perception.

I simply plot orders of magnitude on the y-axis in Figure 3 because I think it would be best for the absolute values of amplitude of oscillation measured in picometers ( $10^{-12}$ meters) to be calibrated in the laboratory by adjusting the constant $\mathrm{c}^{2}$ in Planck's empirical law. The amplitudes of oscillation could vary in detail with chemical composition.

All frequencies throughout the electromagnetic spectrum (Figure 2) coexist at all times and at all locations. What we observe varies in time and space is the intensity of oscillation caused by the amplitude of oscillation at each frequency of oscillation ranging on a logarithmic scale from completely insignificant to dominant.

\section{Heat Physically Is a Two-Dimensional Continuum of Frequencies and Associated Amplitudes of Oscillation}

Planck's empirical law not only shows the physical properties of thermal radiation and the physical properties of oscillators on the surface of solid matter, but also the physical properties that must exist throughout a body of solid matter at thermal equilibrium for that body to "possess" a temperature. Note from Figure 3 that the higher the temperature of the radiating body, the higher the observed amplitude of oscillation at each and every frequency of oscillation and the higher the observed frequencies with the greatest amplitudes of oscillation.

Heat can be defined most fundamentally as that which a body of solid matter must absorb to get warmer and must emit to get cooler. In Figure 3, Earth (green) must absorb the physical properties shaded yellow to become as hot as the filament of an incandescent light bulb. Heat, physically, is thus a two-dimensional continuum of values quantified by subtracting at each and every frequency the amplitude of oscillation as calculated by Planck's law for the cooler body from the amplitude of oscillation for the warmer body. This explains why a body of solid matter can only be warmed by absorbing radiation if that radiation comes from a warmer body, and why the rate that heat flows per second is determined by the difference in temperature (Figure 4)

\section{Thermal Radiation, Heat, and Temperature Are Each Not Additive- They Are Each Averative}

All curves of warming or cooling of solid matter are observed to be asymptotic to the final temperature as shown in Figure 4 for warming. The black curve plots the warming measured per unit time when shining a light on a small piece of thin black metal. The red line shows the warming calculated by multiplying a constant times the final temperature minus the current temperature. The greater the difference in temperature, the greater the flow or flux of heat, and the faster the body is warmed. The greatest temperature difference is in the beginning. As the temperature difference approaches zero asymptotically over time, it takes a very long time to completely warm the body.

You get this same asymptotic shape when approaching a wall by moving the average distance between you and the wall during each unit of time. You get very close to the wall soon, but you will never theoretically reach the wall, although the difference in distance gradually becomes insignificant.

If you take two bodies of solid matter that are identical except for temperature and place them so that heat can flow, the resulting temperature under ideal conditions will be the average of the initial temperatures, not the sum. Temperature 
is not additive; temperature is averative.

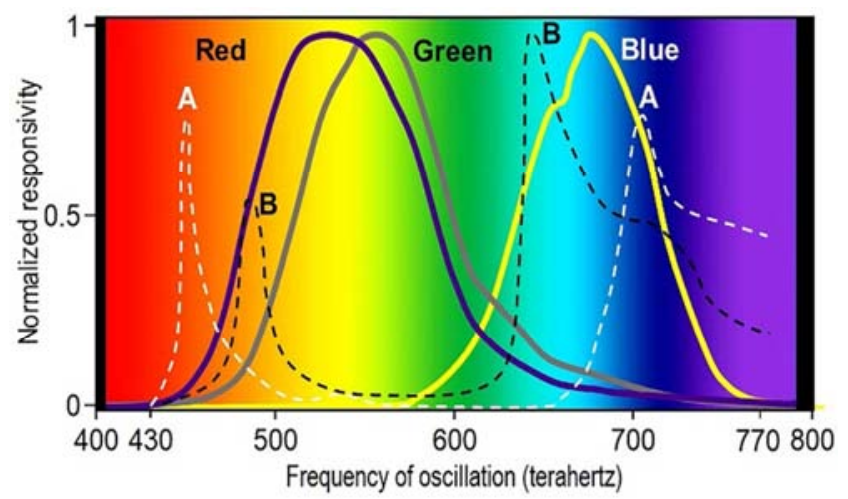

Figure 5. Sets of three cones in your eyes respond in slightly different ways to Red, Green, and Blue light as shown by the solid lines. The dashed lines show the frequencies absorbed by chlorophyll $A$ and chlorophyll $B$.

At each moment in time in Figure 4, the temperature of the absorbing body is averaged with the ultimate temperature, which is determined by the temperature of the emitting body. This averaging is done in Nature by resonance, as described below. The resulting temperature is either the average of the two initial temperatures, or, in the most general case, is somewhere between the two initial temperatures depending on the physical properties of both bodies of solid matter and the boundary conditions.

Averaging instead of adding occurs because temperature is an intensive physical property, which means temperature does not depend on the size or amount of matter involved [24]. Temperature is the result of oscillations at the sub-microscopic level that are spread evenly throughout the body of matter. Therefore, you can divide a body of matter up into as many macroscopic pieces as you wish. Each piece will initially have the same temperature. There is no such thing as a physical amount of temperature. Temperature is simply the result of a level of thermal energy that quantifies how hot we perceive the body to be. Since heat is temperature in transit, it makes no physical sense to think of heat macroscopically as a physical amount of anything. Note in Figure 4 that the rate heat flows per second, the flux, is determined by the difference in temperature.

\section{Heat Flows by Resonance, a Fundamental Physical Property of Oscillatory Systems}

Temperature in solid matter, as described by Planck's empirical law (Figure 3), is the macroscopic result of the simultaneous oscillation of all the sub-microscopic bonds holding a piece of solid matter together. The most important physical property of oscillating systems beyond frequency of oscillation and amplitude of oscillation is resonance, also known as sympathetic oscillation. When two discrete molecular-bond-scale oscillators are oscillating at the same frequency and are within line-of-sight of each other or mechanically connected in some way, they are observed to share amplitude of oscillation essentially instantly. The oscillator with the largest amplitude of oscillation loses amplitude of oscillation to the oscillator with the least amplitude of oscillation. In the simplest case, both oscillators end up with the average of the initial amplitudes of oscillation. Each oscillator can then absorb more amplitude from an oscillator oscillating at the same frequency but at a higher amplitude of oscillation or lose amplitude to an oscillator oscillating at the same frequency but at a lower amplitude of oscillation. When all oscillators oscillating at the same frequency and within line-of-sight or physically connected in some way are oscillating at the same amplitude of oscillation, then resonance can no longer occur, amplitudes of oscillation can no longer "flow".

When this sharing of amplitude is done simultaneously across all frequencies of oscillation between two pieces of solid matter, Planck's law (Figure 3) shows us that the macroscopic temperature of the hotter body becomes a little cooler and the macroscopic temperature of the cooler body becomes a little warmer. For solid matter, when we measure temperature, we are measuring the macroscopic effect of sub-microscopic amplitude of oscillation at each and every frequency of oscillation as calculated by Planck's empirical law. The higher the temperature, the higher the dominant frequencies of oscillation, the higher the amplitude of oscillation at each and every frequency of oscillation, and the higher the average velocity of oscillatory motion. What is "flowing" in an averative manner, which means by averaging, is amplitude of oscillation at each and every frequency of oscillation. When the two pieces of solid matter reach the same temperature, there is no difference in amplitude of oscillation at any frequency, so that no amplitude can "flow". The two pieces of matter are then said to be in a state of thermal equilibrium.

It is extremely important to realize that because all of these sub-microscopic oscillators are frictionless, the only known physical way to increase or decrease the amplitude of oscillation of any molecular-bond-scale oscillator is via resonance. Therefore, the only way for heat to physically flow is by resonance.

Resonance is all around us. We see by resonance. Each of our eyes contains six to seven million cone cells [25] in sets of three that respond to or resonate with visible light in slightly different ways shown by the solid lines in Figure 5 labelled Red, Green, and Blue. Our brain processes the three slightly different neurological signals to detect ten million different shades of color. All cone cells resonate simultaneously, each with a single oscillating molecular bond within your field of view, allowing you to see a whole scene in full color.

The color that an object displays is also related to resonance in an interesting way. For example, a leaf appears green because chlorophyll A and chlorophyll B absorb most red and blue light as shown by the dashed lines in Figure 5, leaving only oscillations in the frequency range of green on the surface of the leaf to resonate with the cells in your eyes 
[26].

We hear by resonance when the tiny hair cells [27] in our inner ear resonate at different frequencies of air pressure, transmitting that precise frequency to our brains. Scientists are beginning to realize, similarly, that a small number of sensor types involving resonance may be what enables animals to recognize a very wide range of smells and tastes [28-31]. We feel temperature by resonance. Resonance appears to be the primary way living things interact with their physical and social environments.

Frequency of oscillation (f), which is the same physical thing as kinetic energy of oscillation $(E=h f$ where $h$ is a constant), is well observed not to change with distance, even galactic distances, except for Doppler effects. Amplitude of oscillation or intensity of radiation, on the other hand, is well observed to decrease with the square of the distance travelled. This decrease can be understood in terms of the apparent density of molecular-bond-scale oscillators on the surface of near and distant bodies. Over short distances, there is a one-to-one correspondence between oscillators. As distance increases, the distant object looks smaller and smaller. Fewer and fewer molecules on the distant surface are able to resonate with each molecule on the near surface. Thus, the amplitude transferred by resonance must then be shared by conduction with more and more similar oscillators on the distant surface as they reach thermal equilibrium. In this way, the rate of amplitude transfer decreases with the square of increasing distance while each frequency of oscillation and its associated amplitude of oscillation based on Planck's empirical law do not change with distance.

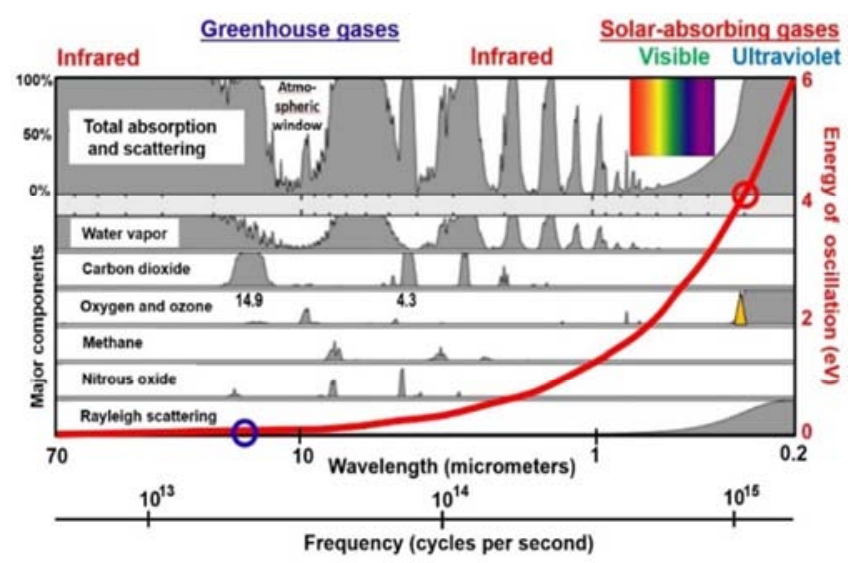

Figure 6. The narrow bands of frequencies of oscillation of the electromagnetic spectrum absorbed by greenhouse gases. Each frequency band is made up in detail by spectral lines similar to those shown in Figure 7 for carbon dioxide. The red line shows the thermal energy $\left(E_{K O}=h f\right)$. Note that ultraviolet-B energy at $0.962 \times 10^{15}$ hertz (red circle) is 3.98 electronvolts while the infrared energy at 14.9 micrometers $20.1 \times 10^{12}$ hertz (blue circle) is only 0.0832 electronvolts, about 50 times less.

At least since Maxwell in 1865 [32], physicists have thought of electromagnetic radiation as an electromagnetic field, a physical three-dimensional entity located in some way between source and receiver whose values can be mapped out by moving an appropriate sensor to different locations. When thinking in terms of resonance, oscillating bonds on the surface of the sensor, which is at some temperature, simply resonate with the oscillating bonds on the surface of the source of the radiation. There does not need to be any physical field.

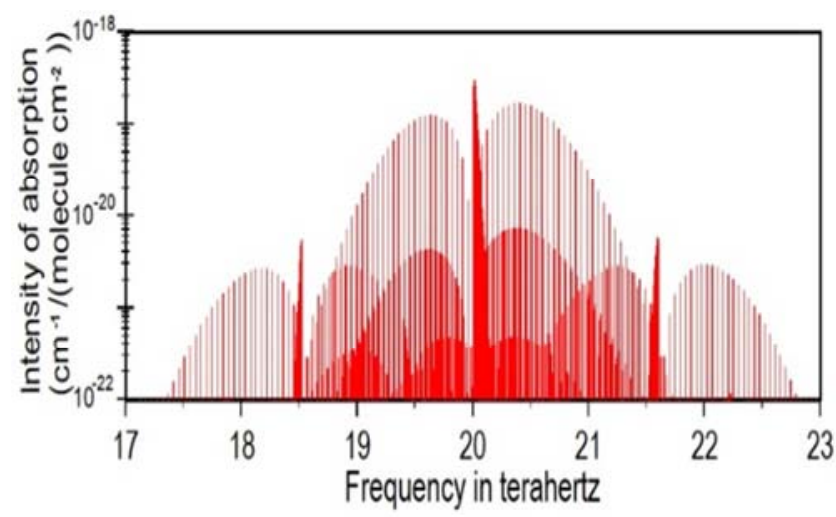

Figure 7. Spectral lines of absorption by a molecule of carbon dioxide in the frequency range of 17 to 23 terahertz, commonly referred to as centered around 14.9 micrometers wavelength.

Resonance is what Einstein called "spooky actions at a distance" [33] where something over here interacts with something over there but we cannot see any physical link between them. Thus, what the concept of quantum entanglement seeks to explain may simply be resonance, a fundamental property of oscillating systems.

Resonance provides a physical explanation for how, physically, a warming system "knows" the final temperature as plotted in Figure 4, how, physically, amplitudes of oscillation and temperatures are averaged, and how, physically, Planck curves (Figure 3) keep their shape. Resonance explains why heat can only flow from hot to cold. Resonance shows that a body of matter does not emit the same radiation in every direction as commonly assumed. Resonance is point to point. For example, Earth, on sides looking at Sun, absorbs heat, amplitudes of oscillation, from a hotter Sun, but on sides not looking at Sun, Earth loses heat at the same time to much colder deep space.

We have a lot to learn about the details of the physics of resonance including how it physically happens over all distances, how rapidly amplitudes are changed, how resonance functions continuously, how resonance in the immediate presence of solid matter explains reflection, refraction, and interference of light, and the effects of the physical properties of the materials involved. But resonance as used in this paper is simply the observation that two sub-microscopic oscillators within-line of sight of each other or mechanically connected in some way share amplitude where the oscillator oscillating at the greatest amplitude of oscillation loses amplitude of oscillation to the oscillator oscillating at the least amplitude of oscillation. Resonance is a fundamental physical property of all oscillating systems contained within matter. Resonance occurs simultaneously at all frequencies of oscillation throughout the very broad spectrum of frequencies that make up electromagnetic radiation at any temperature as shown by Planck's empirical 
law (Figure 3).

\section{Molecules of Gases Absorb Only the Resonant Frequencies of the Bonds Holding the Molecule Together}

Extensive laboratory measurements [34] document spectral lines of absorption for all frequencies of all modes of molecular vibration [35] and their overtones that are so unique, they can be used to identify the chemical composition of any gas from close at hand to deep in space. These spectral lines occur in narrow bands of absorption shown in Figure 6 for major greenhouse gases. An example of the individual spectral lines is shown in Figure 7 for the main absorption band of carbon dioxide, commonly referred to as centering around a wavelength of 14.9 micrometers $\left(20.1 \times 10^{12}\right.$ cycles per second) shown in Figure 6. Water absorbs the majority of infrared frequencies radiated by Earth, but carbon dioxide absorbs less than 16 percent of the frequencies as reported by Ångström in 1900 [36]. In the steady state, the bonds holding gas molecules together can only resonate with the frequencies of oscillation that they absorb. Figure 8 shows Planck's empirical law with frequency on the $\mathrm{x}$-axis plotted logarithmically so that we can resolve the black vertical black lines showing the $16 \%$ of all the frequencies of oscillation radiated by Earth (green) that are absorbed by carbon dioxide and that could then resonate with other matter. Planck's empirical law shows for a body of solid matter to be warmed, it must absorb radiation from a hotter body that contains an increase in amplitude or intensity at each and every frequency of oscillation. Clearly the limited spectral lines of radiation emitted by carbon dioxide could not warm an absorbing body even to the temperature of Earth.

Thus, thermal radiation is absorbed into the bonds holding gas molecules together. In fact, greenhouse gases are simply gases in Earth's atmosphere that have bonds holding three or more atoms together - the greater the number of atoms, the greater the number of bonds, the more "potent" the greenhouse gas as currently calculated. But oscillation of molecular bonds has no direct effect on the temperature of a gas. Temperature of a gas, according to the kinetic theory of gases as discussed above, is proportional to the average kinetic energy of linear motion $\left(\mathrm{E}_{\mathrm{KL}}\right)$, which is equal to one-half the average mass $(\mathrm{m})$ of all gas molecules times their average velocity of linear motion (v) squared: $\mathrm{E}_{\mathrm{KL}}=1 / 2 \mathrm{mv}^{2}$.

For greenhouse gases absorbing infrared radiation from Earth to cause warming of air, you must assume that myriads of collisions cause kinetic energy of oscillation of the bonds to be converted to kinetic energy of linear motion according to the law of equipartition, which assumes that during collision, energy should be shared equally among all nine degrees of freedom. Plus, the kinetic of oscillation absorbed into the bonds of one molecule of carbon dioxide would then, after conversion to kinetic energy of linear motion, have to be shared with 2500 other gas molecules making up a unit of air, assuming a concentration of 0.04 parts per million. It has never been shown by experiment, a cornerstone of the scientific method, that carbon dioxide molecules absorbing terrestrial infrared radiation can heat air in any significant way as explained at JustProveCO2.com and at Physically-Impossible.com. Experiments on Internet claiming to show such warming, use infrared heat lamps more similar to incandescent light bulbs shown in yellow in Figure 3 with filament temperatures around $3300^{\circ} \mathrm{C}$ than to Earth shown in green at $15^{\circ} \mathrm{C}$.

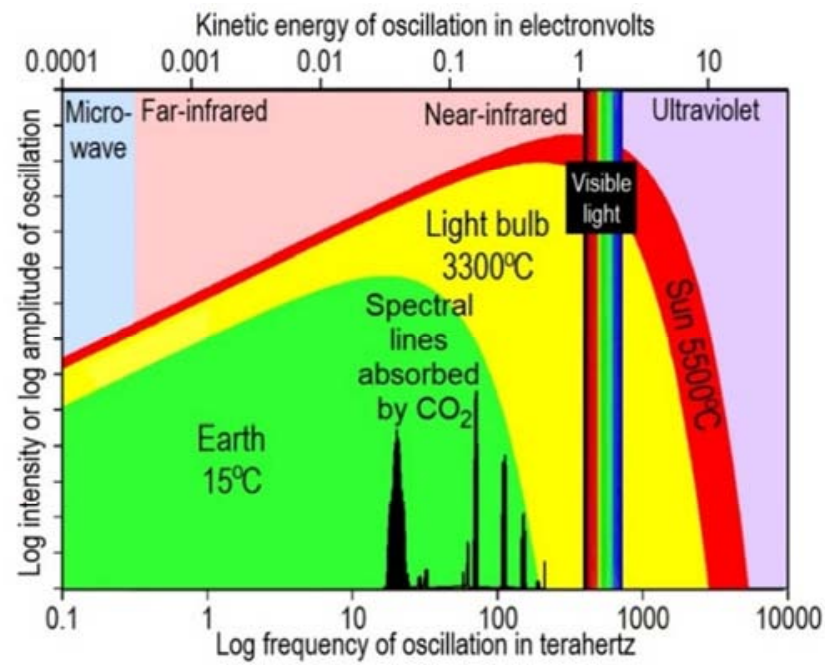

Figure 8. Planck's empirical law with frequency plotted logarithmically. The vertical black lines are the frequencies absorbed by carbon dioxide. The heights of these lines are scaled relative to each other, but the absolute height is simply chosen to make the figure clear.

\section{Photo-Dissociation Converts Kinetic Energy of Oscillation Completely and Efficiently into Gas Temperature}

Gases are observed to be heated when they absorb ultraviolet radiation with energies that are high enough to cause photo-dissociation - to cause the energy of oscillation to exceed $\mathrm{E}_{\mathrm{MAX}}$ in Figure 1-to cause a bond to come apart. When the bond breaks, the molecular pieces fly apart at high velocity, much like the ends of a rubber band that breaks. This recoil efficiently and completely converts the kinetic energy of bond oscillation into kinetic energy of linear motion of the two molecular pieces, increasing the temperature of the gas - the higher the bond energy, the higher the frequency required for dissociation, the higher the velocity of the molecular pieces, the greater the warming of air.

A molecule of oxygen $\left(\mathrm{O}_{2}\right)$ is dissociated into two atoms of oxygen (2O) when the molecule absorbs ultraviolet-C solar radiation with frequencies of oscillation around 1237 terahertz (5.11 electronvolts) [23]. A molecule of ozone $\left(\mathrm{O}_{3}\right)$ is dissociated into a molecule of oxygen $\left(\mathrm{O}_{2}\right)$ and an atom of oxygen $(\mathrm{O})$ when the ozone molecule absorbs ultraviolet- $\mathrm{B}$ solar radiation with frequencies of oscillation around 1176 terahertz (4.86 electronvolts) [23]. A molecule of nitrogen dioxide $\left(\mathrm{NO}_{2}\right)$ is dissociated into nitrogen oxide $(\mathrm{NO})$ and an atom of oxygen $(\mathrm{O})$ when the nitrogen dioxide absorbs violet light with frequencies of oscillation around 714 terahertz (2.95 
electronvolts) [23].

Earth's atmosphere is observed to be warmed daily by tens of degrees as shown in Figure 9 [37, 38]. The troposphere is warmed from below when air comes in physical contact with Earth's sun-warmed surface and then convects upward. Everything above the tropopause, on the other hand, is warmed from above by photo-dissociation. What makes photo-dissociation so effective for warming the stratosphere is that the molecular pieces can recombine when they collide in air, forming a bond with energies less than $\mathrm{E}_{\mathrm{MAX}}$ in Figure 1 and then can be dissociated again as long as the required ultraviolet- $\mathrm{C}$ or ultraviolet-B radiation is still available. Furthermore, photo-dissociation occurs simultaneously everywhere during the day-only varying slightly as a function of time of day and of latitude.

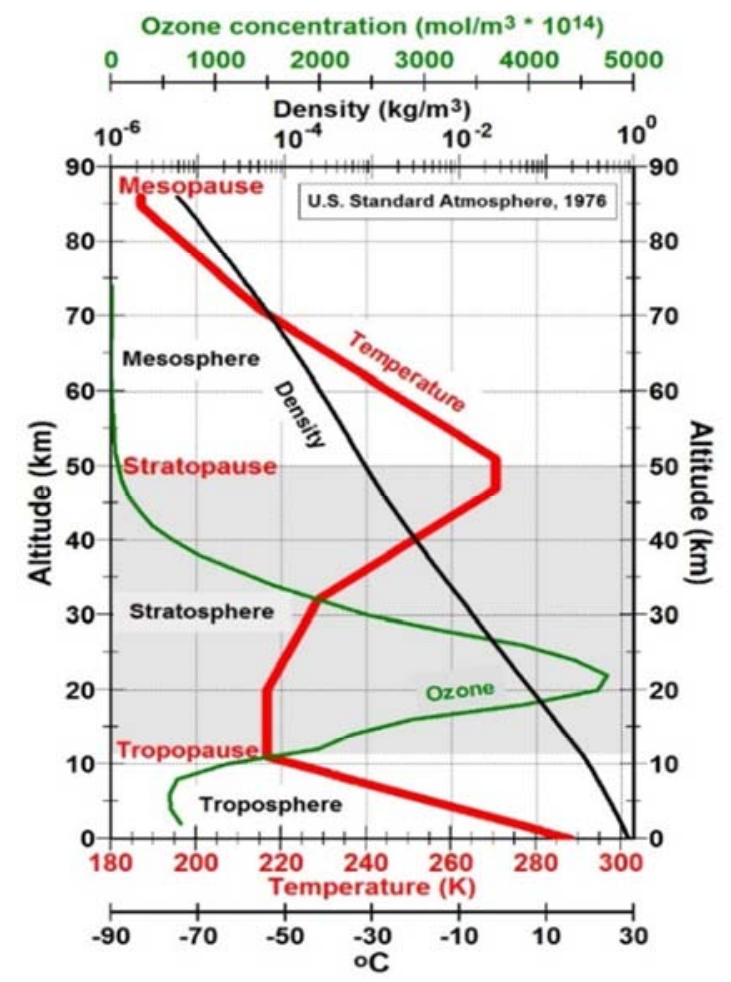

Figure 9. Average temperature, density, and mid-latitude ozone concentration of Earth's atmosphere based on the U. S. Standard Atmosphere (1976).

For ozone and oxygen, this constant dissociation followed by recombination is known as the ozone-oxygen cycle or the Chapman cycle [6]. It is primarily the photo-dissociation of oxygen by solar ultraviolet-C radiation that keeps the stratopause approximately $35^{\circ} \mathrm{C}$ warmer than the tropopause (Figure 9) [37]. All solar ultraviolet-C radiation is absorbed above the tropopause. It is photo-dissociation of ozone by solar ultraviolet-B radiation that warms the lower stratosphere [38]. Most ultraviolet-B radiation is absorbed in the ozone layer. But if the ozone layer is depleted, more ultraviolet-B radiation than usual is observed to reach Earth.

While atmospheric chemists talk about endothermic and exothermic reactions, it is not widely recognized that the energy stored in matter is the kinetic energy of oscillation of all the bonds holding matter together. Photo-dissociation breaks a bond, converting kinetic energy of oscillation into kinetic energy of linear motion, causing increased gas temperature - an exothermic reaction. Recombination, however, is not endothermic. Recombination happens when atoms collide, putting the atoms close enough together so that the bond can be reestablished (Figure 1), allowing oscillation of the bond to resume. In this way, the ozone-oxygen cycle causes warming without reciprocal cooling.

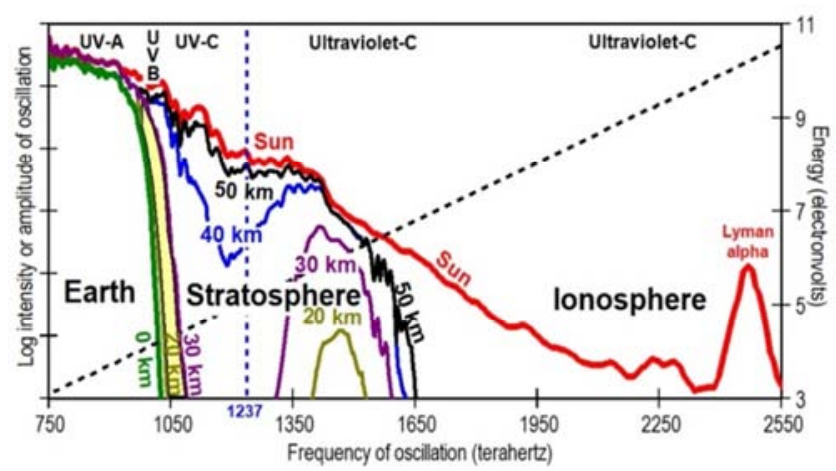

Figure 10. Amplitude or intensity of solar radiation as a function of frequency of oscillation at the top of the atmosphere (red line), and at altitudes of 50, 40, 30,20 , and $0 \mathrm{~km}$. The vertical dashed blue line shows the frequency of 1237 terahertz required to dissociate molecular oxygen $\left(\mathrm{O}_{2}\right)$. The dashed black line shows kinetic energy of oscillation in electronvolts where energy equals the Planck constant times frequency of oscillation $(E=h f)$.

\section{The Highest Energy Solar Radiation Is Absorbed in the Upper Atmosphere}

Earth's dry air contains by volume $78.09 \%$ nitrogen, $20.95 \%$ oxygen, $0.93 \%$ argon, $0.042 \%$ carbon dioxide, and tiny amounts of other gases. Air also contains a highly variable amount of water averaging around $1 \%$ at sea level, but only $0.4 \%$ over the entire atmosphere. Argon is a noble gas that undergoes almost no chemical reactions. Therefore, the structure of the atmosphere is determined primarily by the photochemistry of nitrogen and oxygen making up $99 \%$ of all atoms and molecules in Earth's atmosphere. Since molecular nitrogen $\left(\mathrm{N}_{2}\right)$ has a very strong molecular bond and oxygen $\left(\mathrm{O}_{2}\right)$ has a relatively weak molecular bond, it is primarily the photochemistry of oxygen $\left(\mathrm{O}_{2}\right)$ and ozone $\left(\mathrm{O}_{3}\right)$ that determines which frequencies of solar radiation reach and affect Earth's surface.

Actinic flux is a traditional measure of the total intensity of the light available to be absorbed by a molecule in air. The actinic flux of solar radiation at several altitudes is shown in Figure 10 plotted in units of photons $\mathrm{cm}^{-2} \mathrm{~s}^{-1} \mathrm{~nm}^{-1}$ from Figure 7 of DeMore, Sander, Golden, Hampson, Kurylo, Howard, Ravishankara, Kolb and Molina [39] but labeled intensity or amplitude of oscillation to be consistent with the frequency model of radiation described in this paper. As in Planck's law (Figures 3 and 8), only orders of magnitude are shown. The y-axis scale will need to be changed based on new experimental data.

The red line in Figure 10 shows intensity for solar radiation observed at the top of the atmosphere [40]. The 
black line shows intensity at an altitude of $50 \mathrm{~km}$ near the top of the stratosphere, the blue line at an altitude of $40 \mathrm{~km}$, the yellow shaded area is the main part of the ozone layer between 20 and $30 \mathrm{~km}$, and the green line shows intensity at Earth's surface. It is clear in Figure 10 that most frequencies of solar radiation greater than 1650 terahertz are absorbed above the stratopause at $50 \mathrm{~km}$ (black line) and most frequencies greater than 1050 terahertz are absorbed above the tropopause at an average altitude of $17 \mathrm{~km}$ above equatorial regions and $9 \mathrm{~km}$ above polar regions [41].

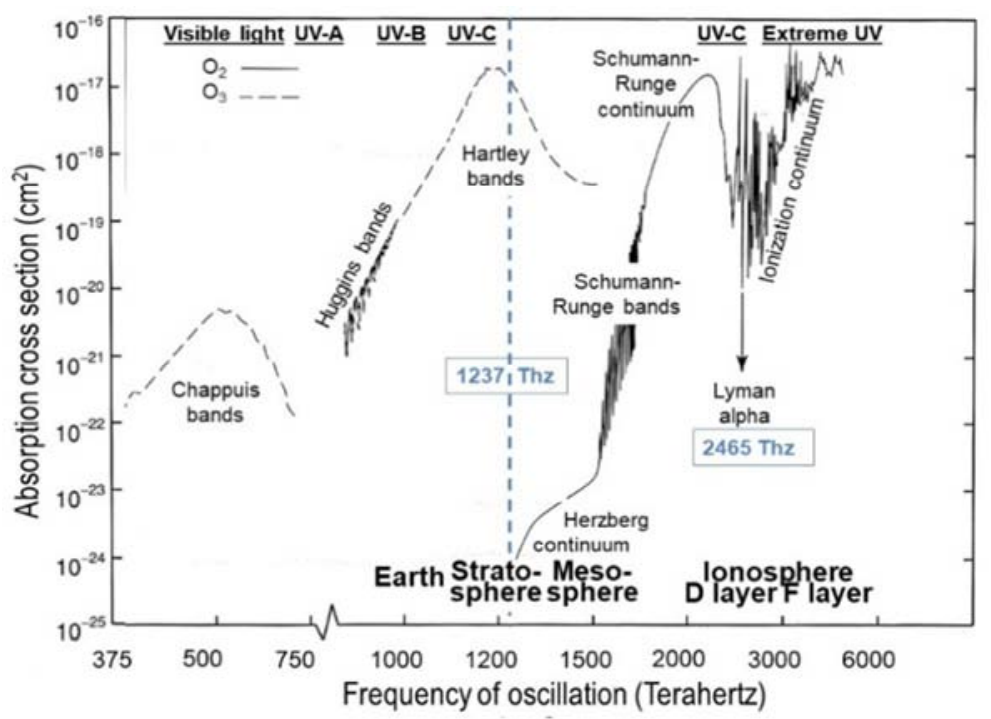

Figure 11. The amount of absorption of solar radiation by oxygen (solid lines) and by ozone (dashed lines) as a function of frequency is low in the Herzberg continuum, just to the right of the 1237 terahertz blue dashed line, explaining the minimal absorption by an altitude of $20 \mathrm{~km}$ between 1350 and 1600 terahertz shown in Figure 5.

High frequency solar radiation, including far ultraviolet from 1500 to 2465 terahertz and extreme ultraviolet from 2465 to 30,000 terahertz, ionize most gas species, forming and heating the ionosphere from $1000 \mathrm{~km}$ down to $60 \mathrm{~km}$ above Earth (Figure 11, which is based on the figure on page 74 of Liou [42]). For example, the F layer of the ionosphere, extending from an altitude of $500 \mathrm{~km}$ down to $150 \mathrm{~km}$, contains the highest electron density in the ionosphere formed primarily by ionizing nitrogen and oxygen when they absorb solar radiation in the frequency range of 30,000 to 3000 terahertz [41]. The Lyman alpha solar radiation peak, centered around 2465 terahertz, ionizes nitric oxide (NO), forming the D layer of the ionosphere at altitudes of 90 to 60 $\mathrm{km}$. The Lyman-Birge-Hopfield absorption bands for nitrogen in the frequency range from 2141 to 1763 terahertz and the Schumann-Runge absorption continuum for oxygen in the frequency range from 2221 to 1703 terahertz (Figures 10 and 11) photo-dissociate nitrogen and oxygen primarily above the mesopause at $85 \mathrm{~km}$ [23].

The stratosphere is warmed primarily by oxygen molecules absorbing solar ultraviolet-C radiation causing photo-dissociation at frequencies in the vicinity of 1237 terahertz (vertical dashed blue line, Figures 10 and 11) and ozone absorbing and being dissociated by ultraviolet- $\mathrm{C}$ and ultraviolet-B in the Hartley bands from 1500 to 1000 terahertz but peaking from 1250 to 1150 terahertz.

Note in Figure 10 the valley in the blue curve for intensity as a function of frequency at an altitude of $40 \mathrm{~km}$. This implies that molecular oxygen $\left(\mathrm{O}_{2}\right)$ is not photo-dissociated by absorbing frequencies greater than 1237 terahertz as commonly assumed but is most strongly dissociated when molecular oxygen absorbs solar radiation with frequencies in the vicinity of 1237 terahertz, at the peak in the Harley bands shown in Figure 11, possibly causing large resonant amplitudes of oscillation sufficient to break the molecular bond. Thus, $\mathrm{E}_{\mathrm{MAX}}$ in Figure 1 may not be a minimum level of kinetic energy or frequency but rather a frequency that resonates with the bond increasing amplitude enough to break the bond.

The sequential photo-dissociation of oxygen and ozone over and over in the ozone-oxygen cycle reproduces about $12 \%$ of the ozone layer each day [43]. This implies that the average lifetime of a single molecule of ozone is only approximately 8.3 days. There is more than enough oxygen to absorb all available solar energy with frequencies in the vicinity of 1237 terahertz. This continual photo-dissociation of oxygen, formation of ozone, and photo-dissociation of ozone is what primarily heats the stratosphere.

It is commonly argued [44] that the warming effect of greenhouse gases is proven by the fact that surface temperatures on Earth without an atmosphere should be around $-18^{\circ} \mathrm{C}$, which is $33^{\circ} \mathrm{C}$ colder than the $15^{\circ} \mathrm{C}$ we enjoy today. Yet $-18^{\circ} \mathrm{C}$ is very close to the average temperature at the stratopause, the top of the stratosphere, the main radiative surface for the Earth-atmosphere system back into space [45]. Clearly Earth is kept warm by the stratospheric blanket heated by absorbing solar ultraviolet radiation.

It is also commonly argued that the surface temperature of Venus is kept at $464^{\circ} \mathrm{C}$ because carbon dioxide, making up $96.5 \%$ of the gases in its atmosphere, absorbs radiation emitted by Venus. It is much more likely that the stratosphere of Venus is heated by photo-dissociation of carbon dioxide at 
frequencies around 1910 terahertz (7.90 electronvolts) [46].

Figures 10 and 11 show that the highest frequencies (energies) of solar radiation are the first to interact with the upper atmosphere, forming the ionosphere. The maximum frequency (energy level) of solar radiation reaching a given altitude generally decreases with altitude controlled primarily by the absorption curves of nitrogen and oxygen that make up $78 \%$ and $21 \%$ of the atmosphere, respectively. General climate models, based on equations by Maxwell [47] and Arrhenius [48], however, currently assume that the level of thermal energy is the same for every frequency. They assume that amount of radiant energy should be on the y-axis of Planck's empirical law and then integrate this amount of energy as a function of frequency, adding microscopic kinetic energies that are not additive. These are the fundamental physical reasons why greenhouse-warming theory is mistaken.

\section{When the Ozone Layer Is Depleted, More Ultraviolet-B Radiation Is Observed to Reach Earth}

Nearly all ultraviolet-C (1071 to 2998 terahertz) and ultraviolet-B (952 to 1071 terahertz) solar radiation has been absorbed by atmospheric gases before penetrating down to an altitude of $20 \mathrm{~km}$ above Earth (Figure 10), forming the ionosphere, mesosphere, and stratosphere. Under atmospheric conditions that were normal before the Antarctic ozone hole began forming around 1970, 97 to 99 percent of ultraviolet-B radiation was absorbed by the ozone layer (yellow shaded area) with the greatest concentration of ozone extending from altitudes of $30 \mathrm{~km}$ down to $15 \mathrm{~km}$ (Figure 9).

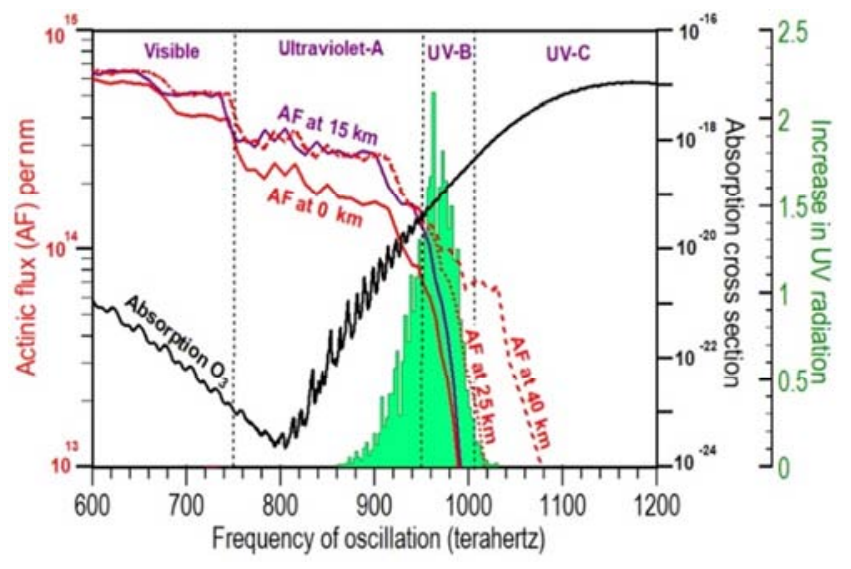

Figure 12. Percent increase in ultraviolet radiation (green) reaching the lower troposphere when the ozone layer is depleted by $1 \%$. These frequencies between 900 and 1000 terahertz are the most energetic solar radiation to reach Earth.

When the ozone layer is depleted, there is less ozone to absorb ultraviolet-B radiation-there is less photo-dissociation taking place in the ozone layer. That is why the temperature of the ozone layer has decreased approximately $2^{\circ} \mathrm{C}$ since $1956[49,50]$. More ultraviolet-B radiation is then observed to reach Earth [51], warming Earth. Figure 12 shows the predicted increase in actinic flux reaching Earth when the ozone layer is depleted by 1\% (3 to 4 Dobson Units, DU) as calculated and discussed by Madronich [52-54]. Note that the frequencies involved are primarily between 900 and 1000 terahertz, with a peak near 967 terahertz. These are the most energetic, "hottest" frequencies of solar radiation that reach Earth's surface.

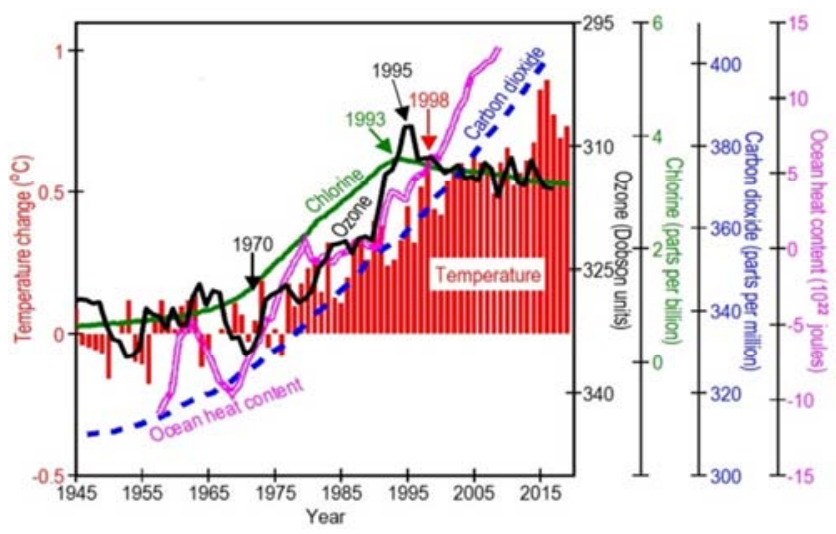

Figure 13. The increase in tropospheric chlorine (green line), caused by manufacturing of chlorofluorocarbon gases, led to increased ozone depletion (black line), which led to increased temperature (red bars).

Planck's empirical law (Figure 3) shows that, in general, the higher the frequency of the radiation, the higher the energy of the radiation, the higher the temperature to which the absorbing body can be raised, and the greater the difference in amplitude or intensity at each frequency between solar radiation and Earth's surface, which means the greater the flux or flow of amplitude per second as shown in Figure 4. In this way, ultraviolet-B radiation warms Earth more effectively than ultraviolet-A radiation, which warms Earth more effectively than visible light, although all three are important. An increase in ultraviolet-B radiation reaching Earth's surface is observed to increase Earth's surface temperature, to increase photodegradation, and to increase your risk of sunburn, premature aging of skin, skin cancer, cataracts, and disruption of DNA.

\section{Ozone Depletion Caused by Humans Appears to Have Warmed the World $0.6^{\circ} \mathrm{C}$ from 1970 to 1998}

The red vertical bars in Figure 13 show global surface temperature anomalies relative to a base period from 1971 through 2000, based on NOAA analysis [55]. The three other major compilations of global temperature data show very similar annual averages [56-58]. Note that temperatures did not change much from 1945 to 1970 , rose sharply beginning around 1970 to 1998 , did not change much from 1998 through 2013, a period known as the global warming hiatus [59], and rose sharply again beginning in 2014, making 2016 the warmest year on record. Meanwhile concentrations of carbon dioxide at Mauna Loa (dashed blue line) [60], rose at 
ever increasing rates, showing no direct relationship to the sudden changes in temperature trend around 1970, 1998, 2014, and after 2016.

In the late 1960s, humans began manufacturing large volumes of chlorofluorocarbon gases (CFCs) for use as refrigerants, spray-can propellants, solvents, and foam blowing agents. CFCs were safer to use than alternatives because of their low toxicity, low reactivity, and low flammability. Emissions of these human-manufactured, chlorine-bearing gases began increasing by 1965 as shown by the green line for total tropospheric chlorine [61]. By 1970, total column ozone measured at Arosa Switzerland [62] began decreasing as shown by the black line smoothed with a five-point, centered, running mean (y-axis inverted).

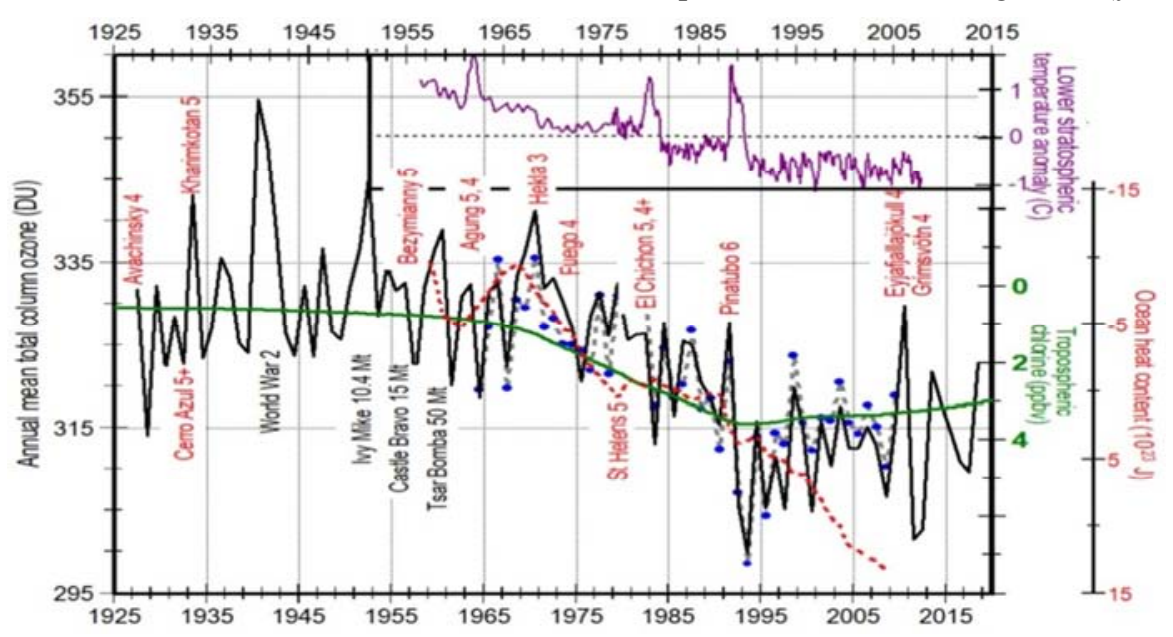

Figure 14. Mean annual total column ozone above Arosa, Switzerland (black line), anthropogenic tropospheric chlorine (green line), ocean heat content (dashed red line) and lower stratospheric temperature anomaly (purple line). Note that the y axes of the green and dashed red lines are inverted. The dashed gray line with blue data markers shows, for 1964 to 2009, the annual mean area-weighted total ozone deviation from the 1964 to 1980 means for northern mid-latitudes.

In 1974, Molina and Rowland [7] discovered when CFCs reach the stratosphere, these very inert molecules can be broken down by solar ultraviolet radiation, releasing atoms of chlorine [7]. They estimated that one atom of chlorine at very cold temperatures could lead to destruction of 100,000 molecules of ozone [7].

When the Antarctic ozone hole was discovered in 1985 [8], scientists and political leaders worked effectively together at the United Nations to frame and pass the Montreal Protocol on Substances that Deplete the Ozone Layer in 1987, mandating cutback in CFC manufacturing beginning in 1989. By 1993, concentrations of chlorine in the troposphere stopped increasing. By 1995, ozone depletion stopped increasing. By 1998, average global temperatures stopped increasing.

Humans, by manufacturing CFCs, appear to have caused the world to warm $0.6^{\circ} \mathrm{C}$ from 1970 to 1998 . Humans, by passing the Montreal Protocol appear to have stopped this increase in warming by 1998 , completing the most definitive experiment ever done concerning the effect of changing concentration of any gas on global temperatures. It is expected to take many decades for the ozone layer to recover to pre-1970 levels [61]. Because CFC concentrations continue to decrease slowly, further increases in global mean temperatures due to CFCs are not anticipated. Without the Montreal Protocol, average global temperatures today would probably be at least $0.5^{\circ} \mathrm{C}$ warmer [63].

Annual mean ozone concentrations remained depleted from 1998 through 2013 by approximately 4\% (13 DU) in northern mid-latitudes compared to pre-1970 concentrations. The resulting increased influx of ultraviolet-B radiation continues to increase ocean heat content (fuchsia double line)
[64] because ultraviolet-B radiation penetrates tens of meters into the ocean [65], from which depth the energy cannot be radiated back into the atmosphere as infrared energy at night. Thus ocean heat content [64] will continue to increase until ozone levels return to levels typical before 1970, widely thought to be many decades in the future [61].

There are many reasons to conclude that global warming from 1970 to 1998 was caused by depletion of the ozone layer. Ozone depletion ranges from zero in the tropics to more than 50\% during late winter-early spring in Antarctica. Similarly, global warming also ranges from zero in the tropics to many degrees in polar regions. The greatest global warming ever recorded by thermometers, $6.7^{\circ} \mathrm{C}$, was of minimum temperatures measured in winter from 1951 to 2003 on the Antarctic Peninsula [66], and this was the greatest warming observed for this region in 1300 years [67]. There was also significant warming in West Antarctica [68] and in the Arctic [69]. Amplification of warming temperatures in polar regions, which has been widely observed, is fully consistent with ozone depletion theory because the greater the ozone depletion, the greater the warming. It is difficult to explain Arctic amplification, which is widely observed, with greenhouse warming theory [70].

The most interesting observation in Figure 13 is that surface air temperature anomalies only rose from 1970 to 1998 as long as the amount of ozone depletion was increasing. When ozone depletion was no longer increasing, a new equilibrium appears to have been established between the amount of ultraviolet-B reaching the lowest atmosphere and the amount of ozone pollution available to be dissociated. Three years after ultraviolet-B radiation stopped increasing in 
1995, surface temperatures reached this new equilibrium, remaining nearly constant from 1998 through 2013 during the global warming hiatus. Global mean surface air temperatures, therefore, appear to be a function of both the amount of ultraviolet-B radiation reaching Earth and the amount of ozone pollution available to be dissociated. Global warming from 1970 to 1998 was twice as great in the northern hemisphere [56] containing $90 \%$ of world population together with most global ozone pollution [71, 72], explaining the urban heat island effect [73, 74]. Similarly, global warming in late 1991 and early 1992 following the 1991 Pinatubo eruption, discussed below, was greatest in industrial areas of central North America and Europe [75]. This implies that the principal increase in air temperature is by photo-dissociation, not by increased ultraviolet-B radiation warming the ground and thereby keeping surface air temperatures warmer at night.

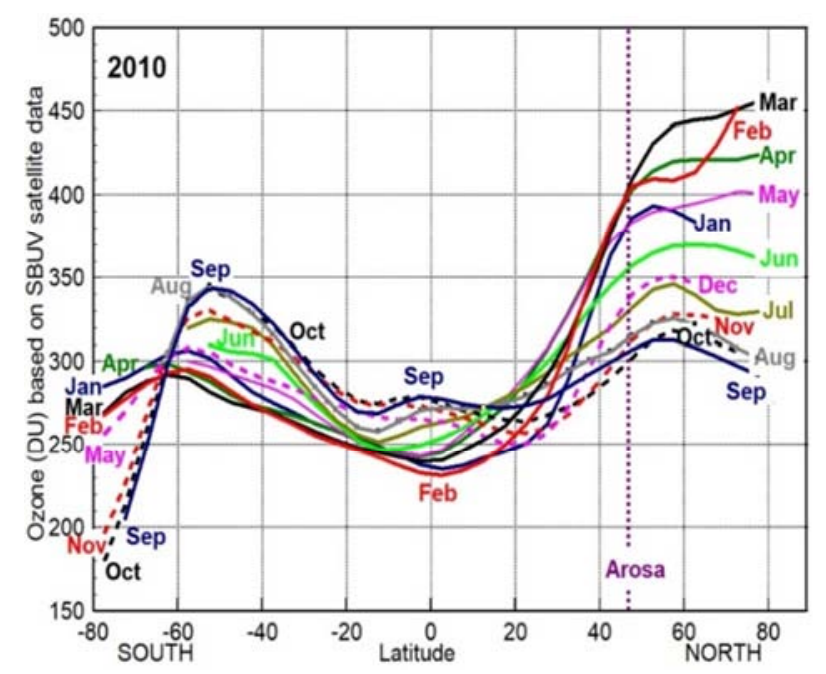

Figure 15. Total column ozone in 2010 plotted as a function of latitude and month of the year. Data from Solar Backscatter Ultraviolet Radiometers $(S B U V)$ flown on several satellites. Vertical dotted line shows the latitude of Arosa Switzerland.

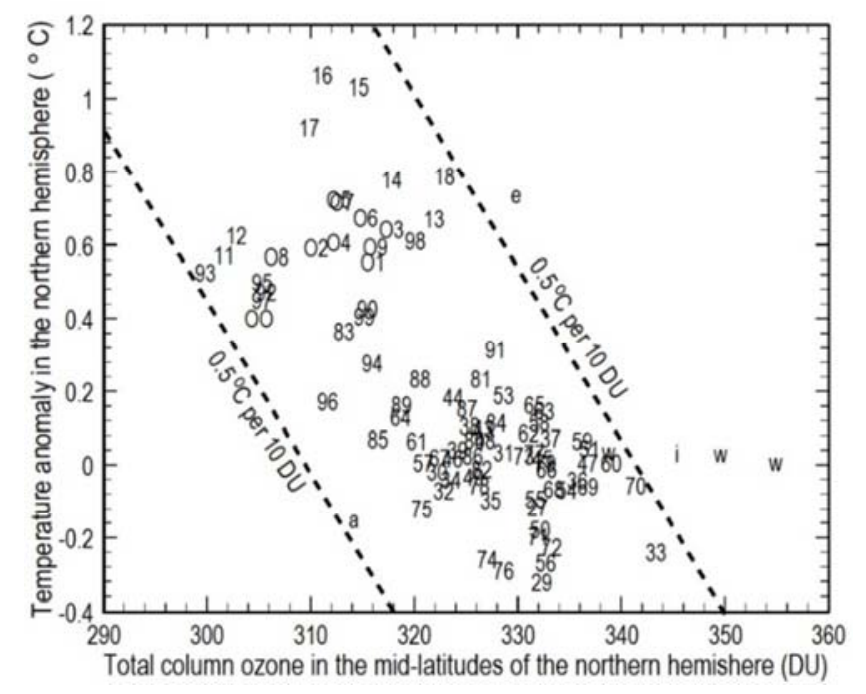

Figure 16. A decrease in yearly total column ozone at mid-latitudes of the northern hemisphere by 30 Dobson Units (DU) corresponds to a $0.9^{\circ} \mathrm{C}$ increase in temperature anomaly in the northern hemisphere. Numbers are the years of observations.

\section{How Annual Mean Total Column Ozone and Temperatures Have Changed Since 1927}

The first routine measurements of total column ozone looking up vertically from Earth began in Arosa Switzerland in 1927 [62]. Ozone concentrations vary substantially by the second, the minute, the hour, the day, and the month. Furthermore, measurements can only be made several times per day under certain conditions. On some days, no measurements can be made. Annual mean ozone observations, the black line in Figure 14, however, show many distinct changes in trend.

The dashed gray line with blue data markers shows, for 1964 to 2009, the annual mean area-weighted total ozone deviation at all stations in northern mid-latitudes $\left(30^{\circ} \mathrm{N}\right.$ to $60^{\circ} \mathrm{N}$ ) compared to 1964 through 1980 means scaled from $-8 \%$ at the bottom of the figure to $10 \%$ at the top [76]. Years of increasing or decreasing ozone are nearly identical for Arosa and for this area-weighted mean with small differences in amplitude. Thus, the Arosa data provide a reasonable approximation for annual mean total column ozone throughout northern mid-latitudes since 1927.

Total column ozone measured at Arosa averaged 331 Dobson Units (DU) from 1927 through 1974, fell 9.4\% to 300 DU by 1993 , began generally rising again until it suddenly fell again to 300 DU in 2011 and has generally been recovering since. The long-term decrease in ozone from around 1970 to the 1995 appears caused by humans as discussed above. The sudden decreases appear caused primarily by volcanic eruptions discussed below.

The purple line in Figure 14 shows cooling of the lower stratosphere while the ozone layer was being depleted. A depleted ozone layer absorbs less ultraviolet-B radiation, causing less warming of the ozone layer. This cooling occurred mostly "as two downward 'steps' coincident with the cessation of transient warming after the major volcanic eruptions of El Chichón and Mount Pinatubo" [49] and a similar downward step following the 1963 eruption of Agung volcano [50]. The transient warming was most likely caused primarily by absorption of solar radiation by megatons of ash and gases injected into the lower stratosphere by these explosive volcanic eruptions, the largest since 1912.

The dashed red line (y-axis inverted) shows the increase in ocean heat content [64] most likely due to increased absorption of ultraviolet-B radiation made available by ozone depletion as discussed below.

The variation of total column ozone as a function of latitude and month is shown in Figure 15 based on data from Solar Backscatter Ultraviolet Radiometers (SBUV) flown on a number of NOAA weather satellites [77]. Note the high values in late winter and the major ozone depletion south of $60^{\circ} \mathrm{S}$ in September to November. 
Annual mean global warming in the northern hemisphere from 1927 through 2013, based on HadCRUT4 temperature anomalies [56], is plotted in Figure 16 on the y-axis as a function of annual mean total column ozone measured at Arosa Switzerland [35] on the X-axis, updated from Ward [78]. These data show a clear, long-term trend of temperature increasing approximately $0.5^{\circ} \mathrm{C}$ as a result of a decrease in ozone of approximately 10 Dobson Units (DU). The numbers in the plot are the last two digits of the years.

There are many reasons for the scatter among the data between the two dashed lines. First warming was not constant since 1927 but was concentrated from 1927 to 1940, from 1970 to 1998, and from 2014 to 2016 (Figure 13). Secondly, the ozone data have many peaks and troughs around a mean ozone curve (Figure 14). Thirdly, volcanic aerosols are well observed to cause cooling of approximately $0.5^{\circ} \mathrm{C}$ for two to three years after major explosive eruptions. I have added $0.4^{\circ} \mathrm{C}$ in 1992 and 1993 following the 1991 eruption of Mt. Pinatubo, the largest volcanic eruption since $1912,0.2^{\circ} \mathrm{C}$ in 1983, 1984, and 1985 following the 1982 eruption of El Chichón, and $0.3^{\circ} \mathrm{C}$ in 1964 and 1965 following the eruption of Agung in 1963, based on conservative estimates of the cooling observed [58]. There were more than 60 smaller volcanic eruptions during this time large enough to cause some cooling, but the data are not clear enough to apply corrections. Data point "a" suggests $0.2^{\circ} \mathrm{C}$ cooling associated with the eruption of Avachinsky in 1926, but documentation is insufficient to apply a correction.

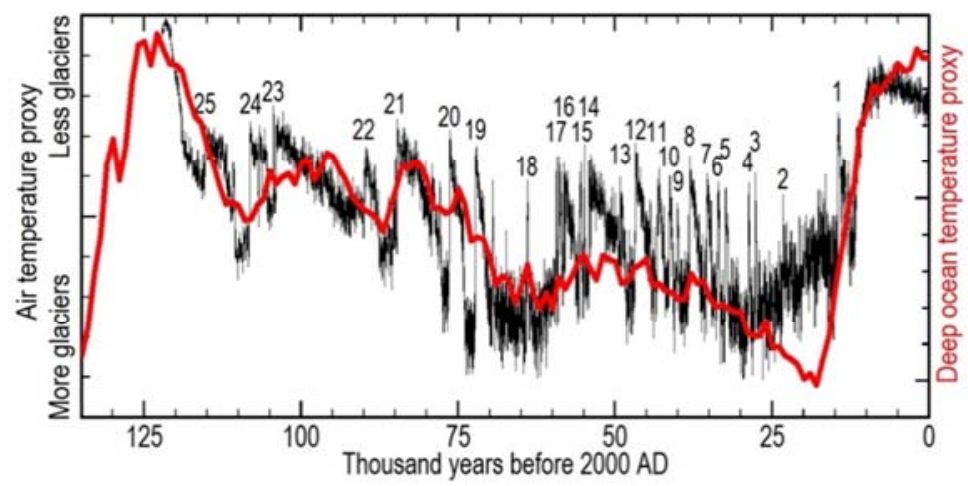

Figure 17. The geologic footprints of global climate change. Twenty-five Dansgaard-Oeschger events of sudden warming of air in Greenland followed by slow, incremental cooling in highly erratic sequences. The black line is air temperature at Summit Greenland during the time the ice formed determined from isotopes of oxygen measured in air bubbles. The red line shows deep ocean temperatures based on oxygen isotope measurements of the shells of foraminifera in deep-sea cores collected at 57 globally distributed sites.

Fourthly, there are many sudden and unexplained increases in ozone. As shown in Figure 14, there was a well observed but poorly understood major release of ozone in 1940, 1941, and 1942 during World War 2 (points w in Figure 16), in 1952 (point i) during the first full-scale atmospheric test of a nuclear fusion device, code named Ivy Mike, and in February 2010 (point e) when a major emission of ozone was observed from satellite data to be emitted from the volcano Eyjafjallajökull in southern Iceland [79, 80]. Typically, ozone levels the year of a volcanic eruption are higher than the previous year (Figure 14), but the amounts vary, and the observations are not detailed enough to apply any corrections. Plus, the reason for this increase is not well understood. We still have much to learn before we can explain the details of the 25 DU spread in ozone at any temperature between the dashed lines in Figure 15, but these data do suggest that global temperatures increase approximately $0.5^{\circ} \mathrm{C}$ when there is a $10 \mathrm{DU}$ decrease in total vertical column ozone.

\section{Large Basaltic Lava Flows Are Contemporaneous with Major, Sudden Global Warming}

On August 29, 2014, Bárðarbunga volcano in central Iceland began extruding basaltic lava over an area of $85 \mathrm{~km}^{2}$ in six months [81], the greatest volume of basalt extruded from any volcano since the eruption of Laki in 1783 [82, 83]. Global warming increased rapidly $0.3^{\circ} \mathrm{C}$ from 2014 to 2016 , more than five-times faster than the warming caused by CFCs from around 1970 to 1998 (Figure 13). The hottest year on record is still 2016. In 2018, the lower Puna eruption [84] in Hawaii, an unusually large eruption for Kilauea volcano, covered an area of $38.5 \mathrm{~km}^{2}$ in just over three months, appearing to cause 2019 and 2020 to be warmer than 2017 and 2018 .

This type of effusive volcanic eruption, common in the rift zones of Iceland, Ethiopia, and Hawaii, extrudes primitive basaltic lava for days, months, centuries, and even hundreds-of-thousands of years [85], emits 10 to 100 times more volatiles per cubic kilometer of magma than major explosive volcanic eruptions [86-89], emits large amounts of chlorine and bromine gases, and heats air to $1200^{\circ} \mathrm{C}$, enhancing convection of chlorine and bromine up into the ozone layer.

Over the past 10,000 years, the seven greatest peaks in global warming were contemporaneous with the seven major peaks in basaltic volcanism covering areas of 700 to $950 \mathrm{~km}^{2}$ in Iceland and in Craters of the Moon National Monument of south-central Idaho [90]. At the end of the last ice age, rapid warming from 15,000 to 14,000 and from 12,000 to 9500 years before present (Figure 17) was contemporaneous with the greatest amounts of volcanic sulfate in ice cores from 
Summit Greenland and with the best dated major basaltic volcanic centers under glaciers in Iceland [91, 92]. All of the 25 Dansgaard-Oeschger sudden warmings (Figure 17) documented in Greenland ice, when local air temperatures rose 10 to $16^{\circ} \mathrm{C}$ in less than 40 years [93], appear, where adequate data exist, to be contemporaneous with basaltic volcanism [91, 94].

Throughout Earth history, extensive extrusion of basaltic lava flows covering areas ranging from tens, to thousands, to millions of square kilometers were contemporaneous with major global warming, the larger the flow, the greater the warming [78, 95-99]. Ernst [99] documents 211 large igneous provinces (LIP) [85] which, where well documented, are typically contemporaneous with major warming, highly acidic oceans, major mass extinctions, and times of sudden change in types of sediments and fossils [98]. For example, between 251 and 250 million years ago, basaltic lavas covered an area in Siberia of 7 million $\mathrm{km}^{2}$, the size of the 48 contiguous United States less Texas and Montana. Oceans were warmed to hot tub temperatures [100] with massive depletion of the ozone layer [101-104]. This was the time of the greatest mass extinction known in Earth history.

Extensive evidence throughout Earth history for sudden warming contemporaneous with extrusion of basaltic lavas over large areas and associated ozone depletion is described in detail at OzoneDepletionTheory. info. More than $75 \%$ of all volcanism on Earth occurs on mid-ocean ridges and other submarine areas where eruptive gases do not reach the atmosphere. The submarine eruptions have no direct effect on global climate, although they do cause acidification and warming of oceans.

\section{Major Explosive Volcanic Eruptions Form Stratospheric Aerosols that Cause Slow Global Cooling}

The greatest, sudden depletion of ozone shown in Figure 14 was in 1992 and 1993, following the June 1991 eruption of Mt. Pinatubo in the Philippines, the largest volcanic eruption since 1912. Pinatubo ejected 491 to 921 megatons of water vapor and 17 megatons of sulfur dioxide [105] into the lower stratosphere where these gases circled Earth and spread to $30^{\circ} \mathrm{N}$ and $10^{\circ} \mathrm{S}$ within 21 days [106], spreading worldwide within months and lasting for a few years.

Some sulfur dioxide may have been dissociated by ultraviolet-C frequencies of solar radiation in the vicinity of 1500 terahertz, 6.20 electronvolts, [107] (Figure 10) leading to sudden warming of the lower stratosphere as observed (purple line, Figure 14). Plus, volcanic ash in the lower stratosphere absorbing solar radiation probably increased this one-year spike in warming.

The main effect of the water vapor and sulfur dioxide, however, was to form a sulfuric acid aerosol that spread around the world, whose particle sizes grew large enough (up to $0.5 \mu \mathrm{m} \mathrm{[108])} \mathrm{to} \mathrm{reflect} \mathrm{and} \mathrm{scatter} \mathrm{solar} \mathrm{radiation}$ attaining a mid-visible optical depth of 0.3 within months
[109], causing cooling of surface temperatures by 0.4 to $0.6^{\circ} \mathrm{C}$ through 1993 [105].

From December 1991 through February 1992, when ozone concentrations would normally be increasing during Arctic winter, as shown in Figure 15, warming of up to $3^{\circ} \mathrm{C}$ was observed in the lower troposphere over Canada, northern Europe, and Siberia [75], suggesting ozone depletion. Pinatubo erupted 3 to 16 megatons of chlorine [110] plus bromine and fluorine as high as $35 \mathrm{~km}$ into the middle of the stratosphere [105].

Tabazadeh and Turco [111] argue that chlorine is water soluble in the form of $\mathrm{HCl}$ and would, therefore, primarily be rained out of the eruption cloud, leaving only the $\sim 1 \%$ increase in stratospheric chlorine observed [112, 113]. But not much chlorine may be needed because the aqueous surfaces of the aerosol particles provide the chemical conditions for heterogeneous reactions observed to cause ozone depletion [114] where one atom of chlorine can destroy 100,000 molecules of ozone [7]. Tabazadeh and Turco conclude that chlorine in the stratosphere is caused more by manufactured CFCs than by volcanoes. The data in Figure 14 show, however, that depletion at mid-latitudes following the eruption of Mt. Pinatubo within two years was in addition to and slightly more than the depletion caused by CFCs that cumulated over the previous 21 years. Plus, bromine erupted by volcanoes would likely play a major role in ozone depletion $[115,116]$. This volcano-caused ozone depletion appears in Figure 14 to recover in less than ten years, while CFCs, which are highly inert except when broken down by ultraviolet-C, are expected to remain in the atmosphere for many more decades [61].

The second largest depletion of ozone was of a similar amount in 2011 and 2012, following the much smaller eruptions in Iceland of Eyjafjallajökull during March-April 2010 and Grímsvötn during May 2011.

The years with the other large eruptions plus a few smaller basaltic effusive eruptions in Iceland are labeled in red together with their Volcanic Explosivity Index (VEI) [117] in Figure 14. An eruption with VEI equal to or greater than 5 usually forms a major aerosol layer, cooling Earth. It is clear in Figure 14 that volcanic eruptions deplete the ozone layer especially during the two years following the eruption.

Note also in Figure 14 that the year of eruption typically shows an increase in ozone, while the next two years show a much greater decrease. Ward [79, 80] documents from satellite data a $70 \%$ increase in total column ozone beginning on February 19, 2010, northeast of Eyjafjallajökull, precisely at the time when earthquakes and deformation data suggest magma started moving toward the surface from a dike at a depth of 4.5 to $6.5 \mathrm{~km}$ [118]. The origin of this ozone is not understood. There are also ozone peaks in the years of major nuclear tests labeled in black and a very large and enigmatic peak during World War 2.

We still have much to learn about the detailed chemistry of ozone depletion as a function of latitude and time of year. The mechanism for ozone depletion proposed by Molina and Rowland [7] caused by CFCs appears to be very important 
for forming the Antarctic ozone hole in late winter and early spring, but may not explain ozone depletion at mid-latitudes and throughout the year. Aerosols formed by major explosive volcanic eruptions appear to provide the aqueous surfaces that promote ozone depletion. But how, in detail, does the chlorine and bromine emitted by effusive, basaltic lava flows cause observed ozone depletion? Is it simply by enhanced convection over these very hot lavas?

In Figure 14, nearly all major explosive volcanic eruptions in recorded history [119] with VEI equal to 5 or greater, are followed by cooling of global surface temperatures by approximately $0.5^{\circ} \mathrm{C}$ for two or more years. Modelling shows that this short-term cooling of the whole ocean surface following the eruption of Krakatoa in 1883 penetrated into deeper ocean layers, where it persisted for more than a century [120]. Modeling also shows that several explosive volcanic eruptions each century cool the oceans incrementally [121]. When such activity persists over tens of thousands of years, the oceans are cooled incrementally down into ice-age conditions [95] (red line in Figure 17).

\section{The Geologic Footprints of Global Climate Change}

The most detailed and accurate measurements of changing air temperatures over the past 122,000 years have been made by analyzing ice cores from 3-kilometer deep holes through Greenland ice [122]. The black line in Figure 17 shows a proxy for air temperatures at Summit Greenland. Temperature is estimated by measuring oxygen isotopes in air bubbles trapped when compacting snow turns to ice. The temporal resolution of each sample ranges from yearly near the top of the core to twenty years near the bottom of the core.

The black line in Figure 17 documents twenty-five "dramatic climatic fluctuations known as DansgaardOeschger (D-O) events, during which oceanic and atmospheric conditions alternated between full glacial (so-called stadial) and relatively mild (interstadial) conditions [123, 124]. Ice-core records resolve the most recent of the D-O events in sub-annual detail, and analysis of these high- resolution records suggests that fundamental atmospheric circulation changes took place in just a few years [125-127]. About 25 abrupt transitions from [colder] stadial to [warmer] interstadial conditions took place during the Last Glacial period and these vary in amplitude from $5^{\circ} \mathrm{C}$ to $16^{\circ} \mathrm{C}$, each completed within a few decades" [122].

Each of these highly asymmetric events starts with sudden warming typically within years, followed by slow incremental cooling over millennia, in erratic sequences that average a few thousand years in length. These sequences are not cyclic. They are asymmetric (saw toothed) and they are highly erratic. It appears that basaltic eruptions cause rapid warming of air and rapid warming of the mixed layer just below the surface of oceans. Not long after these eruptions stop, deeper, colder ocean water appears to cool the mixed layer and air back into ice-age conditions.

The red line in Figure 17 shows average deep-ocean temperatures determined by stacking data from 57 globally distributed drilling sites where oxygen isotopes measured in shells of foraminifera record the temperature of the water at the time the animal was living [128]. It takes millennia to change deep ocean temperatures because of the very large heat content of oceans and because of slow mixing vertically between thermal layers and horizontally by ocean currents. The red line shows quite clearly the slow, incremental, but not linear cooling over the last 120,000 years. While ocean temperatures (red line) are changing over millennia, air temperatures (black line) are changing radically every few thousand years. Climate has been changing far more rapidly than most climate scientists realize.

The black line shows air temperature only at Summit Greenland while the red line shows global deep-sea water temperatures. The sudden warming out of the depths of the last ice age approximately 18,000 years before present is contemporaneous with extensive eruptions of Mount Takahe basaltic shield volcano in Marie Byrd Land, Antarctica, $76^{\circ} \mathrm{S}$, and other eruptions in the southern hemisphere [129].

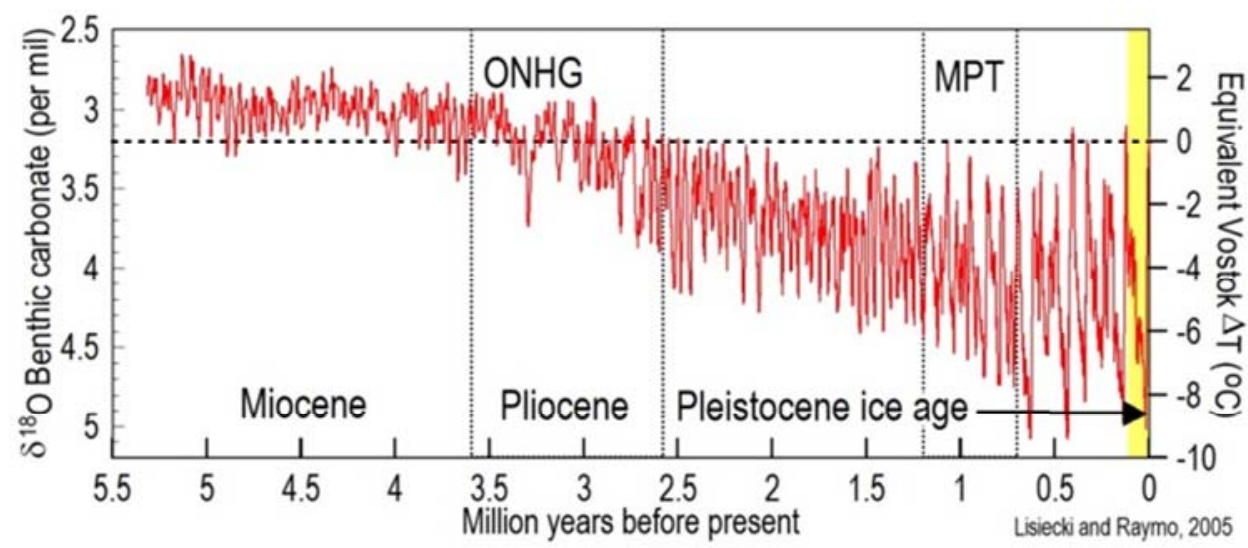

Figure 18. Climate record for the past 5.5 million years based on a stack of 57 globally distributed benthic cores where oxygen isotopes of foraminifera shells. ONHG is the onset of northern hemisphere glaciation. MPT is the Mid-Pleistocene Transition. The yellow shading shown the most recent 135,000 years plotted in Figure 17. 
The red line in Figure 18 shows this same dataset of stacked deep-ocean temperatures extending back to 5.32 million years ago. The onset of northern hemisphere glaciation (ONHG) began soon after 3.5 million years ago in the Pliocene. In the mid-Pliocene, however, global temperatures were 2 to $3{ }^{\circ} \mathrm{C}$ warmer than today, global sea level was 25 meters higher, and concentrations of carbon dioxide were similar [130]. Ice sheets in the northern hemisphere began growing much larger 2.588 million years ago at the beginning of the Pleistocene ice age. Temperatures decreased gradually until 18,000 years before present (red line in Figure 17), while the amplitude of oscillation in temperature increased from a range of around $2^{\circ} \mathrm{C}$ in the Miocene to nearly $10^{\circ} \mathrm{C}$ during the depth of the Pleistocene ice age. The lower the temperature of the ocean, the greater the extent of continental glaciation, and the greater the difference in temperature between stadial and interstadial times.

The most widely accepted hypothesis for the cause of ice ages and for the apparent cycling of global temperatures into and out of ice-age conditions is that variations in Earth's orbit around Sun cause cyclic variation in how much solar radiation reaches Earth's surface [131]. These so-called Milankovitch cycles [132] vary over a period of approximately 100,000 years due to changes in the eccentricity of Earth's orbit, over a cycle of 41,000 years due to changes in Earth's axial tilt, and over a cycle of 26,000 years due to precession of Earth's axis. There has been considerable effort to look for these specific periods of oscillation in the data. Even the data plotted in Figures 17 and 18 have been "minimally tuned" to these periods where possible within known errors [128]. But an advanced method for singular spectrum analysis suggests "that orbital forcings did not have a major role in guiding the Plio-Pleistocene climate system response" [133]. Plus, as shown in this paper, the footprints of climate change, in detail, are not cyclic. Climate change clearly consists of erratic sequences of sudden global warming followed by slow cooling that average only a few thousand years in duration.
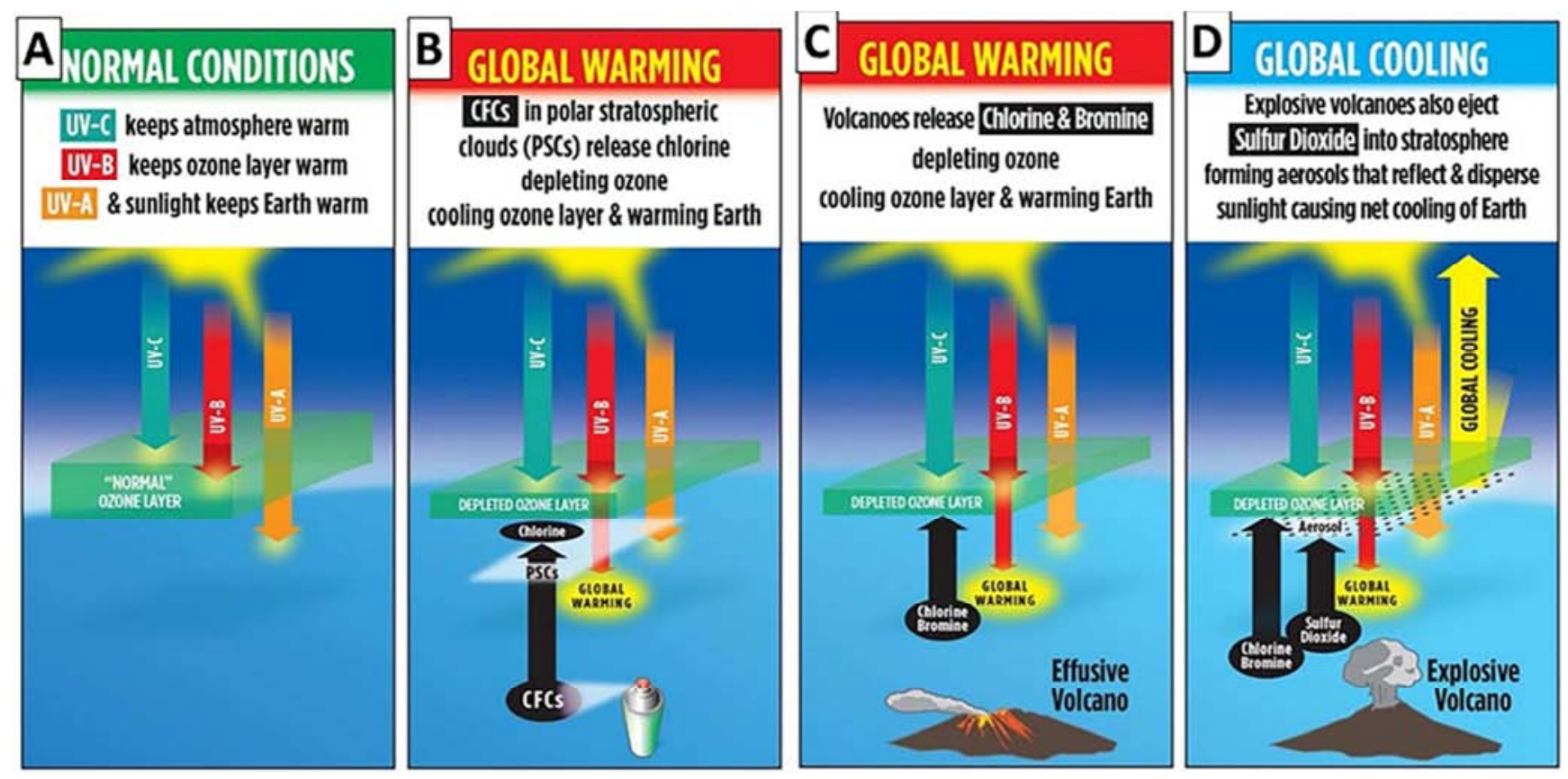

Figure 19. A) Conditions normal before 1965. Most UV-B absorbed in the ozone layer. B) CFCs release atoms of chlorine that deplete the ozone layer allowing more UV-B to reach Earth. C) Effusive volcanoes emit chlorine and bromine, which deplete ozone, leading to global warming. D) Explosive volcanoes similarly deplete ozone, but form globe-encircling aerosols that reflect, scatter, and absorb solar radiation, causing net global cooling.

While this rapid sequencing of air temperature is best documented only in the past 122,000 years, there is no reason to think such sequences have not been dominant throughout Earth history. Surdam [134] documents sequences of sudden warming followed by slower cooling averaging about 5000 years in the very finely layered Eocene Green River Formation in Wyoming. Giles [135] documents very rapid changes throughout most of the Paleozoic, but these older data cannot be resolved to within a few thousand years. The delicate balance between these two types of volcanism is observed throughout Earth history and is, most likely, determined by the detailed motions of tectonic plates [136] - explosive volcanoes are more common where plates are converging, effusive volcanoes are more common where plates are spreading apart.
Any theory proposed to explain global climate change must provide a clear and direct explanation for these clearly-observed footprints of climate change: 1) sudden warming within years, 2) slow, incremental cooling over millennia, 3) in highly erratic sequences averaging a few thousand years in length, 4) in glacial cycles often lasting 50,000 to 100,000 years $[133,137,138]$.

The photochemistry of these sequences is summarized in Figure 19. Part A): Under normal conditions, 97 to 99 percent of ultraviolet-B solar radiation is absorbed in the ozone layer and Earth is heated primarily by ultraviolet-A and visible radiation. $\mathrm{B}$ ): When CFCs are manufactured, the chlorine they release depletes the ozone layer, so that more ultraviolet-B radiation reaches Earth, cooling the ozone layer and warming 
Earth. C): Effusive volcanic eruptions of basalt release chlorine and bromine that can similarly deplete the ozone layer causing rapid global warming. D): Explosive volcanoes similarly release chlorine and bromine that deplete the ozone layer causing warming during the first winter, but also form sulfuric-acid aerosols in the lower stratosphere that reflect and disperse sunlight causing net global cooling of around $0.5^{\circ} \mathrm{C}$ for several years. Several such large explosive eruptions per century increment the oceans cooler and cooler over millennia down into ice-age conditions.

The length of the few-thousand-year sequences appears determined by how frequently major basaltic, effusive eruptions occur. This may vary over geologic time scales depending on the configuration of tectonic plates and how many regions of rifting there are containing active sub-aerial basaltic eruptions. One possible explanation for the length of glacial cycles is that it takes approximately 100,000 years to store enough water in glaciers on land and lower sea level enough so that more basaltic volcanism becomes sub-aerial. There were a few times in the Precambrian known as Snowball Earth when glaciers covered all continents before major rifting most likely warmed the world again [139, 140]. Another possibility is that as the thickening ice layer increases pressure on shallow magma systems, it takes approximately 100,000 years to accumulate enough shallow magma in the system to have extensive enough eruptions to completely melt the ice sheet.

\section{Changes in Concentrations of Ozone Affect Weather}

Daily maps of total column ozone [141] and their animations [80, 142] show that ozone concentrations vary substantially every day over areas of thousands of square kilometers, especially at mid-latitudes and in polar regions, and especially in winter and spring. Typically $12 \%$ of the ozone layer is photo-dissociated and re-created every day through the ozone-oxygen cycle [43]. Photo-dissociation increases air temperature. Thus, the presence of ozone implies that the air containing the ozone is warmer than nearby air at the same altitude containing less ozone. But these relationships are complicated by observations that air masses can travel around the globe at least once during the average lifetime of only 8.3 days for an ozone molecule. Furthermore, the presence of ozone means that more ultraviolet-B solar radiation is absorbed in the atmosphere so that less ultraviolet-B radiation reaches Earth, cooling Earth's surface. In these ways, regional changes in ozone concentrations are highly likely to be linked closely with regional changes in weather.

Increased ozone depletion is observed to make the polar vortex stronger, colder, and more persistent [143]. Changes in ozone concentrations cause changes in the shape and extent of the polar jet streams that can cause changes in regions where excessive Arctic cold dips south into the eastern United States, Northern Europe, and Russia and changes in the latitudes where drought and excessive precipitation occur.

Ozone concentrations also change vertically, affecting the height of the tropopause, the boundary between air heated from below by a sun-warmed Earth and air heated from above by solar radiation causing photo-dissociation. For example, on June 19, 2004, the height of the tropopause above Montreal, Canada, was observed to drop from 13 to 8 $\mathrm{km}$ in 12 hours as total column ozone concentrations rose from 300 to 380 DU [144].

In 1950, Reed [145] described the role of vertical motions in ozone-weather relationships. He noted that "maximum positive deviations of daily values [of temperatures] from the monthly means are generally found to the rear of surface low-pressure areas, while maximum negative deviations are found to the rear of surface highs," and that "for many occlusions, the maximum positive deviations occur directly over the surface low rather than to the rear." With the advent of satellite systems, it is now possible to observe these variations with great precision.

During March 2020, one of the largest ozone holes ever observed in the Arctic opened up over an area about three times the size of Greenland [146]. Temperatures from December to February were $3.2^{\circ} \mathrm{C}$ above average south of this hole, especially in northern Europe and northern Russia [147].

Regional changes in ozone concentrations may also play a key role in teleconnections, causing "recurring and persistent, large-scale patterns of pressure and circulation anomalies that spans vast geographical areas" [148] affecting such things as the El Niño-Southern Oscillation. There is much detail to work out, but we need to start with the recognition that because of photo-dissociation, regional differences in concentrations of ozone in the troposphere and lower stratosphere affect air temperatures and, therefore, weather.

\section{Conclusions}

All the bonds holding solid matter together are not rigid. They are observed to oscillate at frequencies of trillions of cycles per second (Figure 1). Thermal energy contained within solid matter is the simultaneous existence of kinetic energy of oscillation of all these bonds at all frequencies of oscillation in the electromagnetic spectrum (Figure 2). Thermal energy in electromagnetic radiation is the simultaneous existence of kinetic energy of oscillation transmitted through air and space by a plethora of these molecular-bond-scale oscillators through motion of charge in the same way, at each frequency, that a radio transmitter transmits its single frequency of oscillation.

Planck's empirical law (Figure 3) calculates the observed amplitude of oscillation at each frequency of oscillation as a function of the temperature of the radiating body of solid matter. The higher the temperature, the higher the amplitude of oscillation at each and every frequency of oscillation and the higher the frequencies of oscillation with the greatest amplitudes 
of oscillation. All frequencies throughout the electromagnetic spectrum coexist at all times and at all locations. What we observe varies in time and space is the amplitude of oscillation at each frequency of oscillation ranging on a logarithmic scale from completely insignificant to dominant.

Heat is what a body of matter must absorb to become hotter or lose to become colder. The physical properties of heat are defined by Planck's empirical law based on the temperature of the radiating body minus Planck's empirical law based on the temperature of the absorbing body. The amount of heat that flows is directly proportional to the difference in temperature (Figure 4).

What "flows" is amplitude of oscillation by resonance, also known as sympathetic oscillation. When two discrete molecular-bond-scale oscillators are oscillating at the same frequency and are within line-of-sight of each other or mechanically connected in some way, they are observed to share amplitude of oscillation essentially instantly. The oscillator with the largest amplitude of oscillation loses amplitude of oscillation to the oscillator with the least amplitude of oscillation. In the simplest case, both oscillators end up with the average of the initial amplitudes of oscillation. Thermal energy, heat, and temperature are each averaged together, they are each averative, not additive as currently assumed in physics and in climate science. Since these oscillators are frictionless, the only way we know to decrease or increase the amplitude of oscillation of these oscillators is via resonance. Resonance is a fundamental property of oscillating systems and is the primary way that living things appear to interact with their physical and social environments.

A body of solid matter can only be warmed by increasing the amplitude of oscillation at each and every frequency of oscillation as specified by Planck's empirical law (Figure 3). Such warming can only be done by absorbing radiation if that radiation comes from a warmer body of solid matter that contains higher amplitudes of oscillation at each and every frequency of oscillation. Heat only flows from greater amplitude of oscillation to lesser amplitude of oscillation, which is from greater temperature to lesser temperature. A body of matter cannot be heated in any way by absorbing its own radiation, as assumed by greenhouse-warming theory, because its own radiation does not contain the higher amplitudes of oscillation required for heat to flow.

Every day, air is heated when it comes in contact with Earth's sun-warmed surface and convects upward, heating the troposphere from below (Figure 9). Air in the stratosphere, on the other hand, is heated every day from above when high-energy, solar ultraviolet radiation causes photo-dissociation of oxygen, ozone, and many other gas species. Upon dissociation, the molecular pieces fly apart at high velocity, converting kinetic energy of oscillation of the bond immediately and completely into kinetic energy of linear motion, which is proportional to temperature of a gas.

Depletion of the ozone layer caused by humans manufacturing CFC gases (Figure 13) and by volcanic eruptions (Figure 14) is observed to cause rapid global warming. This warming is greatest in the most populated regions where ultraviolet-B radiation photo-dissociates ground-level ozone pollution. Major explosive volcanic eruptions are observed to form sulfuric-acid aerosols in the lower stratosphere that reflect and scatter sunlight, cooling the world approximately $0.5^{\circ} \mathrm{C}$ for a few years. When several major explosive volcanic eruptions occur per century and continue for millennia, they are observed to cool oceans slowly, incrementally down into ice-age conditions (red line, Figure 17). These aerosols and ozone depletion have the primary effects on climate because they cause changes in temperature globally.

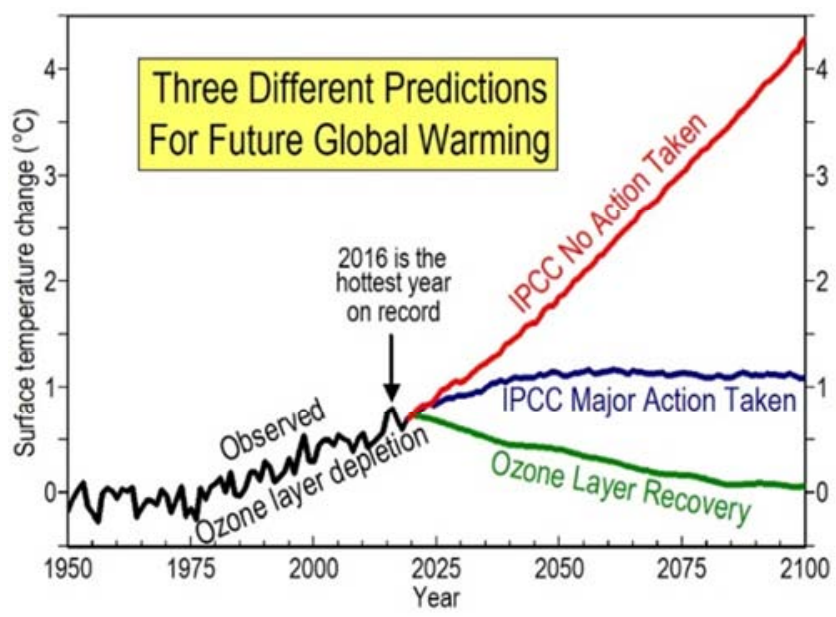

Figure 20. The Intergovernmental Panel on Climate Change (IPCC) predicts several degrees of warming by 2100 (red line). They predict that if major action is taken immediately to reduce greenhouse-gas emissions, warming might be kept to only one an additional degree (blue line). Ozone depletion theory, on the other hand predicts gradual cooling of climate over the next several decades unless there is a major new source of ozone depletion (green line).

Greenhouse-warming theory assumes that greenhouse gases absorbing infrared radiation emitted by Earth cause, in one way or another, average air temperatures at Earth's surface to get warmer. But no surface can get warmer by absorbing its own radiation. Furthermore, infrared radiation from Earth absorbed most strongly by carbon dioxide has around 60 times less energy than the energy required to photo-dissociate oxygen or ozone. Infrared radiation is absorbed into the bonds holding the greenhouse-gas molecules together, which has no direct effect on the temperature of air. Greenhouse-warming theory is based on the assumption that heat, radiative forcing, is a flux that is additive. But temperature, heat, and thermal energy are each not additive - they are each averative.

Climate models based on greenhouse-warming theory predict major warming by 2100 as shown by the red line in Figure 20. The Intergovernmental Panel on Climate Change (IPCC) is urging world leaders to spend trillions of dollars immediately to reduce greenhouse-gas emissions to prevent major warming and hopefully limit temperatures to the blue curve. If ozone depletion is the primary cause of global warming as described in this paper, global temperatures should slowly cool as shown by the 
green line, provided there is no unexpected increase in ozone depletion.

\section{Conflict of Interest}

The author declares no competing interests.

\section{References}

[1] L. Vanhaelewyn, E. Prinsen, D. Van Der Straeten and F. Vandenbussche, Hormone-controlled UV-B responses in plants. Journal of experimental botany, 67 (2016) 4469-4482.

[2] J. Fina, R. Casadevall, H. AbdElgawad, E. Prinsen, M. N. Markakis, G. T. Beemster and P. Casati, UV-B inhibits leaf growth through changes in growth regulating factors and gibberellin levels. Plant Physiology, 174 (2017) 1110-1126.

[3] N. G. Jablonski, The evolution of human skin and skin color. Annual Reviews of Anthropology, 33 (2004) 585-623.

[4] N. G. Jablonski and G. Chaplin, The evolution of skin pigmentation and hair texture in people of African ancestry. Dermatologic Clinics, 32 (2014) 113-121.

[5] L. Deng and S. Xu, Adaptation of human skin color in various populations. Hereditas, 155 (2018) 1.

[6] S. Chapman, A theory of upper-atmospheric ozone. Memoirs of the Royal Meteorological Society, 3 (1930) 103-125.

[7] M. J. Molina and F. S. Rowland, Stratospheric sink for chlorofluoromethanes: Chlorine catalysed destruction of ozone. Nature, 249 (1974) 810-814.

[8] J. C. Farman, B. G. Gardiner and J. D. Shanklin, Large losses of total $\mathrm{O}_{3}$ in atmosphere reveal seasonal $\mathrm{ClO}_{\mathrm{x}} / \mathrm{NO}_{\mathrm{x}}$ interaction. Nature, 315 (1985) 207-210.

[9] Nobel Prize in Chemistry, (1995) https://www.nobelprize.org/ prizes/chemistry/1995/summary/.

[10] J. C. Grossman, Thermodynamics: Four laws that move the Universe The Great Courses, Course 1291 (2014) https://www.thegreatcourses.com/courses/thermodynamics-fo ur-laws-that-move-the-universe.html.

[11] P. M. Morse, Diatomic molecules according to the wave mechanics. II. Vibrational levels. Physical Review, 34 (1929) 57-64.

[12] R. J. Le Roy, N. S. Dattani, J. A. Coxon, A. J. Ross, P. Crozet and $\mathrm{C}$. Linton, Accurate analytic potentials for $\mathrm{Li}_{2}\left(\mathrm{X}^{1} \Sigma+\mathrm{g}\right)$ and $\mathrm{Li}_{2}\left(\mathrm{~A}^{1} \Sigma^{+\mathrm{u}}\right)$ from 2 to $90 \AA$, and the radiative lifetime of $\mathrm{Li}(2 \mathrm{p})$. Journal of Chemical Physics, 131 (2009) 204309.

[13] J. Guignard, Human sensitivity to vibration. Journal of sound and vibration, 15 (1971) 11-16.

[14] Wikipedia, Electromagnetic spectrum (2020) https://en. wikipedia. org/ wiki/Electromagnetic_spectrum.

[15] M. Planck, On the theory of the energy distribution law of the normal spectrum. Verhandlungen der Deutschen Physikalischen Gesellschaft, 2. (1900)

[16] M. Rute and P. Sérgio, Classroom fundamentals: measuring the Planck constant. Science in School, 28 (2014) 28-33; https://ScienceInSchool.org/sites/default/files/teaserPdf/issue2 8 planck.pdf.
[17] M. Planck, Entropie und temperatur strahlender wärme. Annalen der Physik, 306 (1900) 719-737.

[18] A. Einstein, On a heuristic point of view about the creation and conversion of light. Annalen der Physik, 322 (1905) 132-148.

[19] G. N. Lewis, The conservation of photons. Nature, 118 (1926) 874-875.

[20] C. A. Gearhart, Max Planck and black-body radiation, in Max Planck: Annalen Papers, D. Hoffmann, Editor. (2008), Wiley-VCH, 395-418.

[21] Nobel Prize in Physics, (1918) https://www.nobelprize.org/ prizes/physics/1918/summary/.

[22] H. Kragh, Max Planck: the reluctant revolutionary. Physics World, 13 (12); (2000)

[23] B. J. Finlayson-Pitts and J. N. Pitts, Chemistry of the upper and lower atmosphere: Theory, experiments, and applications. (1999), San Diego: Academic Press. 969.

[24] Wikipedia, Intensive and extensive properties (2020) https://en.wikipedia.org/wiki/Intensive_and_extensive_prop erties.

[25] Wikipedia, Cone cell (2020) https://en.wikipedia.org/wiki/ Cone_cell.

[26] Wikipedia, Chlorophyll (2020) https://en.wikipedia.org/wiki/ Chlorophyll.

[27] Wikipedia, Hair cell (2020) https://en.wikipedia.org/wiki/ Hair_cell.

[28] C. Burr, The emperor of scent: A true story of perfume and obsession. (2004): Random House. 352 p.

[29] G. W. S. Piesse, The art of perfumery: Method of obtaining the odors of plants. (2015): CreateSpace Independent Publishing Platform. 368 p.

[30] C. Bushdid, M. O. Magnasco, L. B. Vosshall and A. Keller, Humans can discriminate more than 1 trillion olfactory stimuli. Science, 343 (2014) 1370-1372.

[31] R. S. Carney, Parallel and sequential sequences of taste detection and discrimination in humans. eNeuro, 6 (1) e0010-19.2019 (2019) 1-2.

[32] J. C. Maxwell, A dynamical theory of the electromagnetic field. Philosophical Transactions of the Royal Society of London, 155 (1865) 459-512.

[33] M. Born, A. Einstein and H. Born, Born-Einstein Letters: Friendship, politics, and physics in uncertain times. (1971): Macmillan. 235 p.

[34] E. Gordon, L. S. Rothman, C. Hill, R. V. Kochanov, Y. Tan, P. F. Bernath, M. Birk, V. Boudon, A. Campargue and K. Chance, The HITRAN2016 molecular spectroscopic database. Journal of Quantitative Spectroscopy and Radiative Transfer, 203 (2017) 3-69.

[35] Wikipedia, Molecular vibration (2020) https://en.wikipedia. org/wiki/Molecular_vibration.

[36] Ångström, Ueber die bedeutung des wasserdampfes und der kohlensäure bei der absorption der erdatmosphäre. Annalen der Physik, 308 (1900) 720-732. 
[37] Committee on Extension to the Standard Atmosphere, U. S. Standard Atmosphere, 1976. (1976), Washington, D. C.: U. S. Government Printing Office. 241 p.

[38] J. Krueger and R. A. Minzner, A mid-latitude ozone model for the 1976 US standard atmosphere. Journal of Geophysical Research, 81 (1976) 4477-4481.

[39] W. DeMore, S. Sander, D. Golden, R. Hampson, M. Kurylo, C. Howard, A. Ravishankara, C. Kolb and M. Molina, Chemical kinetics and photochemical data for use in stratospheric modeling, Evaluation number 12. NASA JPL Publication, 97-4 (1997) p. 260, Figure 7, https://jpldataeval.jpl.nasa.gov/ pdf/Atmos97_Anotated.pdf.

[40] C. Gueymard, The sun's total and spectral irradiance for solar energy applications and solar radiation models. Solar Energy, 76 (2004) 423-453.

[41] Wikipedia, Ionosphere (2020) https://en.wikipedia.org/wiki/ Ionosphere.

[42] N. Liou, An introduction to atmospheric radiation. (2002): Academic Press. 583 p.

[43] Wikipedia, Ozone-oxygen cycle (2020) https://en.wikipedia. org/wiki/Ozone-oxygen_cycle.

[44] G. Elert, The physics factbook. https://hypertextbook.com/ facts/2005/JudyTang.shtml, (2016).

[45] J. France, V. Harvey, C. Randall, M. Hitchman and M. Schwartz, A climatology of stratopause temperature and height in the polar vortex and anticyclones. Journal of Geophysical Research: Atmospheres, 117 (2012).

[46] Y. Matsumi, N. Shafer, K. Tonokura, M. Kawasaki, Y. L. Huang and R. J. Gordon, Doppler profiles and fine - structure branching ratios of $\mathrm{O}\left({ }^{3} \mathrm{P}_{j}\right)$ from photodissociation of carbon dioxide at $157 \mathrm{~nm}$. Journal of Chemical Physics, 95 (1991) 7311-7316.

[47] J. C. Maxwell, A treatise on electricity and magnetism. Vol. 1. (1873), Oxford: Clarendon Press. 560.

[48] S. Arrhenius, On the influence of carbonic acid in the air upon the temperature of the ground. Philosophical Magazine and Journal of Science Series 5, 41 (1896) 237-276.

[49] D. W. J. Thompson and S. Solomon, Understanding recent stratospheric climate change. Journal of Climate, 22 (2009) 1934-1943.

[50] W. J. Randel, Variability and trends in stratospheric temperature and water vapor, in The Stratosphere: Dynamics, Transport and Chemistry. Geophysical Monograph, 190 (2010) 123-135.

[51] J. R. Herman, Global increase in UV irradiance during the past 30 years (1979-2008) estimated from satellite data. J. Geophys. Res, 115 (2010) D04203.

[52] S. Madronich, Trends and predictions in global UV, in The Role of the Stratosphere in Global Change, M. L. Chanin, Editor. (1993), Springer-Verlag: Berlin, 463-471.

[53] S. Madronich, R. L. McKenzie and M. M. Caldwell, Changes in ultraviolet radiation reaching the earth's surface. Ambio, 24 (1995) 143-52.

[54] S. Madronich, R. L. McKenzie, L. O. Björn and M. M. Caldwell, Changes in biologically active ultraviolet radiation reaching the Earth's surface. Journal of Photochemistry and Photobiology B: Biology, 46 (1998) 5-19.

[55] NOAA, Climate at a glance (2020) https://www.ncdc.noaa. gov/cag/global/time-series.

[56] HadCRUT4, Temperature (2020) https://crudata.uea.ac.uk/cru/ data/temperature/.

[57] GISS, GISS surface temperature analysis (2020) https:// data.giss.nasa.gov/gistemp/faq/abs_temp.html.

[58] Berkeley Earth, Global average surface temperature (2020) $\mathrm{http}: / /$ berkeleyearth.lbl.gov/auto/Global/Land_and_Ocean_co mplete.txt.

[59] J. C. Fyfe, G. A. Meehl, M. H. England, M. E. Mann, B. D. Santer, G. M. Flato, E. Hawkins, N. P. Gillett, S.-P. Xie, Y. Kosaka, et al., Making sense of the early-2000s warming slowdown. Nature Climate Change, 6 (2016) 224-228.

[60] NOAA, Annual mean $\mathrm{CO}_{2}$ at Mauna Loa (2020) https://www. esrl.noaa.gov/gmd/ccgg/trends/\#mlo_full.

[61] S. Solomon, Stratospheric ozone depletion: A review of concepts and history. Reviews of Geophysics, 37 (1999) 275-316.

[62] J. Staehelin, P. Viatte, R. Stübi, F. Tummon and T. Peter, Stratospheric ozone measurements at Arosa (Switzerland): history and scientific relevance. Atmospheric Chemistry and Physics, 18 (2018) 6567-6584.

[63] P. L. Ward, J8.3 Mario Molina's research not only led to the solution for the antarctic ozone hole, but it led to the solution for global warming caused by humans since 1960 American Meteorological Society Annual Meeting (2016) https://ams.confex.com/ams/96Annual/webprogram/Paper284 695.html, Video: https://youtu.be/NF438LDeqLA.

[64] S. Levitus, J. Antonov, T. Boyer, O. Baranova, H. Garcia, R. Locarnini, A. Mishonov, J. Reagan, D. Seidov and E. Yarosh, World ocean heat content and thermosteric sea level change (0-2000 m), 1955-2010. Geophysical Research Letters, 39 (2012) L10603.

[65] M. Tedetti and R. Sempéré, Penetration of ultraviolet radiation in the marine environment. A review. Photochemistry and Photobiology, 82 (2006) 389-397.

[66] G. L. Hughes, S. S. Rao and T. S. Rao, Statistical analysis and time-series models for minimum/maximum temperatures in the Antarctic Peninsula. Proceedings of the Royal Society A: Mathematical, Physical and Engineering Science, 463 (2006) 241-259.

[67] R. Mulvaney, N. J. Abram, R. C. A. Hindmarsh, C. Arrowsmith, L. Fleet, J. Triest, L. C. Sime, O. Alemany and S. Foord, Recent Antarctic Peninsula warming relative to Holocene climate and ice-shelf history. Nature, 489 (2012) 141-144.

[68] D. H. Bromwich, J. P. Nicolas, A. J. Monaghan, M. A. Lazzara, L. M. Keller, G. A. Weidner and A. B. Wilson, Central West Antarctica among the most rapidly warming regions on Earth. Nature Geoscience, 6 (2013) 139-145.

[69] K. E. Trenberth, P. D. Jones, P. Ambenje, R. Bojariu, D. Easterling, A. K. Tank, D. Parker, F. Rahimzadeh, J. A. Renwick, M. Rusticucci, et al., Observations: Surface and atmospheric climate change, in Climate Change 2007: The 
Physical Science Basis. Contribution of Working Group I to the Fourth Assessment Report of the Intergovernmental Panel on Climate Change, S. Solomon, D. Qin, M. Manning, Z. Chen, M. Marquis, K. B. Averyt, M. Tignor and H. L. Miller, Editors. (2007), Cambridge University Press, 235-336.

[70] C. Serreze and R. G. Barry, Processes and impacts of Arctic amplification: A research synthesis. Global and Planetary Change, 77 (2011) 85-96.

[71] R. B. Kavia, R. Dasgupta and C. J. Fowler, Functional imaging and the central control of the bladder. Journal of Comparative Neurology, 493 (2005) 27-32.

[72] D. Fowler, M. Amann, R. Anderson, M. Ashmore, P. Cox, M. Depledge, D. Derwent, P. Grennfelt, N. Hewitt and O. Hov, Ground-level ozone in the 21 st century: future trends, impacts and policy implications. Royal Society Science Policy Report, 15 (2008) 148 p. https://royalsociety.org/ /media/royal_ society_content/policy/publications/2008/7925.pdf,

[73] Wikipedia, Urban heat island (2020) https://en.wikipedia. org/wiki/Urban_heat_island.

[74] EPA, Heat island effect (2016) https://www.epa.gov/ heatislands.

[75] A. Robock, Pinatubo eruption: The climatic aftermath. Science, 295 (2002) 1242-1244

[76] Douglass, V. Fioletov, S. Godin-Beekmann, R. Müller, R. Stolarski, A. Webb, A. Arola, J. Burkholder, J. Burrows and M. Chipperfield, Chapter 2: Stratospheric ozone and surface ultraviolet radiation, in Scientific Assessment of Ozone Depletion: 2010, C. A. Ennis, Editor. (2011), World Meteorological Organization Global Ozone Research and Monitoring Project - Report No. 52, 76 p. https://www.esrl.noaa. gov/csl/assessments/ ozone/2010/summary/ch2.html.

[77] NASA, 1970-2018 Profile and Total Column Ozone from the SBUV Instrument Series (2020) http://acd-ext.gsfc.nasa. gov/Data_services/merged/data/sbuv.v86.mod_v8.70-16.za.txt

[78] P. L. Ward, Ozone depletion explains global warming. Current Physical Chemistry, 6 (2016) 275-296.

[79] P. L. Ward, Increases in total column ozone before volcanic eruptions (2020) https://ozonedepletiontheory.info/preeruption-ozone.html.

[80] P. L. Ward, Increase in total column ozone Before the 2010 eruption of Eyjafjallajökull (2020) https://ozonedepletion theory.info/ImagePages/eyjafjallajokull-ozone-animation.html

[81] F. Sigmundsson, A. Hooper, S. Hreinsdóttir, K. S. Vogfjörd, B. G. Ofeigsson, E. R. Heimisson, S. Dumont, M. Parks, K. Spaans and G. B. Gudmundsson, Segmented lateral dyke growth in a rifting event at Bárðarbunga volcanic system, Iceland. Nature, 517 (2015) 191-195.

[82] T. Thordarson and S. Self, Atmospheric and environmental effects of the 1783-1784 Laki eruption: A review and reassessment. Journal of Geophysical Research, 108 (2003) 4011.

[83] T. Gudmundsson, K. Jónsdóttir, A. Hooper, E. P. Holohan, S. A. Halldórsson, B. G. Ófeigsson, S. Cesca, K. S. Vogfjörd, F. Sigmundsson, T. Högnadóttir, et al., Gradual caldera collapse at Bárdarbunga volcano, Iceland, regulated by lateral magma outflow. Science, 353 (2016) 262.

[84] Wikipedia, 2018 lower Puna eruption (2020) https://en. wikipedia.org/wiki/2018_lower_Puna_eruption.

[85] Wikipedia, Large igneous province (2020) https://en.wikipedia. org/wiki/Large_igneous_province.

[86] J. Palais and H. Sigurdsson, Petrologic evidence of volatile emissions from major historic and pre-historic volcanic eruptions, in Understanding Climate Change. Geophysical Monograph, 52 (1989) 31-56.

[87] C. Freda, D. Baker and P. Scarlato, Sulfur diffusion in basaltic melts. Geochimica et Cosmochimica Acta, 69 (2005) 5061-5069.

[88] S. Self, S. Blake, K. Sharma, M. Widdowson and S. Sephton, Sulfur and chlorine in late Cretaceous Deccan magmas and eruptive gas release. Science, 319 (2008) 1654-1657.

[89] A. Jambon, B. Deruelle, G. Dreibus and F. Pineau, Chlorine and bromine abundance in MORB: the contrasting behaviour of the Mid-Atlantic Ridge and East Pacific Rise and implications for chlorine geodynamic cycle. Chemical Geology, 126 (1995) 101-117.

[90] P. L. Ward, Plate tectonics controls global climate change by determining the frequency of major explosive, subduction-related volcanic eruptions causing incremental global cooling versus the extent of subaerial, rift-related, effusive, basaltic lava flows causing sudden global warming, ocean acidification, mass extinctions, and often the ends of geologic eons, eras, periods, etc. Geological Society of America Annual Meeting (2017) https://ozonedepletion theory.info/Papers/Ward2017GSASlidesLINEAR.pdf.

[91] J. M. Licciardi, M. D. Kurz and J. M. Curtice, Glacial and volcanic history of Icelandic table mountains from cosmogenic ${ }^{3} \mathrm{He}$ exposure ages. Quaternary Science Reviews, 26 (2007) 1529-1546.

[92] P. L. Ward, Volcanoes both cool and warm earth's climate (2020) https://ozonedepletiontheory.info/volcanoes-and-climate.html.

[93] P. L. Ward, Abrupt climate warming is associated with effusive volcanism (2020) https://ozonedepletiontheory.info/abruptclimate-warming.html.

[94] G. A. Zielinski, P. A. Mayewski, L. D. Meeker, S. Whitlow and M. Twickler, A 110,000-year record of explosive volcanism from the GISP2 (Greenland) ice core. Quaternary Research, 45 (1996) 109-118.

[95] P. L. Ward, What really causes global warming? Greenhouse gases or ozone depletion? (2016), New York: Morgan James Publishing. $237 \mathrm{p}$.

[96] P. L. Ward, What really causes global warming? Greenhouse gases or ozone depletion? (2020) https://whyclimate changes.com/.

[97] P. L. Ward, The ozone depletion theory of global warming (2020) https://ozonedepletiontheory.info/.

[98] V. E. Courtillot and P. R. Renne, On the ages of flood basalt events. Comptes Rendus Geoscience, 335 (2003) 113-140.

[99] E. Ernst, Large Igneous Provinces. (2014): Cambridge University Press. $653 \mathrm{p}$. 
[100] Y. Sun, M. M. Joachimski, P. B. Wignall, C. Yan, Y. Chen, H. Jiang, L. Wang and X. Lai, Lethally hot temperatures during the early triassic greenhouse. Science, 338 (2012) 366-370.

[101] A. Black, J.-F. Lamarque, C. A. Shields, L. T. Elkins-Tanton and J. T. Kiehl, Acid rain and ozone depletion from pulsed Siberian Traps magmatism. Geology, (2013) G34875. 1.

[102] H. Svensen, S. Planke, A. G. Polozov, N. Schmidbauer, F. Corfu, Y. Y. Podladchikov and B. Jamtveit, Siberian gas venting and the end-Permian environmental crisis. Earth and Planetary Science Letters, 277 (2009) 490-500.

[103] J. P. Benca, I. A. Duijnstee and C. V. Looy, UV-B-induced forest sterility: Implications of ozone shield failure in Earth's largest extinction. Science Advances, 4 (2018) e1700618.

[104] S. Lindström, H. Sanei, B. Van De Schootbrugge, G. K. Pedersen, C. E. Lesher, C. Tegner, C. Heunisch, K. Dybkjær and P. M. Outridge, Volcanic mercury and mutagenesis in land plants during the end-Triassic mass extinction. Science Advances, 5 (2019) eaaw4018.

[105] S. Self, J.-X. Zhao, R. E. Holasek, R. C. Torres and A. J. King, The atmospheric impact of the 1991 Mount Pinatubo eruption, in Fire and Mud: Eruptions and lahars of Mount Pinatubo, Philippines, C. G. Newhall and R. S. Punongbayan, Editors. (1996), Philippine Institute of Volcanology and Seismology and University of Washington Press, https://pubs.usgs.gov/ pinatubo/self/, 1089-1115.

[106] M. McCormick, Initial assessment of the stratospheric and climatic impact of the 1991 Mount Pinatubo eruption-Prologue. Geophysical Research Letters, 19 (1992) 149.

[107] D. Hydutsky, N. Bianco and A. Castleman Jr, The photodissociation of $\mathrm{SO}_{2}$ between 200 and $197 \mathrm{~nm}$. Chemical Physics, 350 (2008) 212-219.

[108] S. Asano, A. Uchiyama and M. Shiobara, Spectral optical thickness and size distribution of the Pinatubo volcanic aerosols as estimated by ground-based sun photometry. Meteorological Society of Japan Bulletin, 71 (1993) 165-173.

[109] P. B. Russell, J. M. Livingston, E. G. Dutton, R. F. Pueschel and others, Pinatubo and pre-Pinatubo optical depth spectra: Mauna Loa measurements, comparison, inferred particle size distribution; radiative effects, and relationship to Lidar data. Journal of Geophysical Research, 98 (1993) 22,969-22,985.

[110] M. Gerlach, H. R. Westrich and R. B. Symonds, Preeruption vapor in magma of the climactic Mount Pinatubo eruption: Source of the giant stratospheric sulfur dioxide cloud, in Fire and mud: Eruptions and lahars of Mount Pinatubo, Philippines, C. G. Newhall and R. S. Punongbayan, Editors. (1996), Philippine Institute of Volcanology and Seismology and University of Washington Press, https://pubs.usgs. gov/pinatubo/gerlach/, 415-433.

[111] A. Tabazadeh and R. P. Turco, Stratospheric chlorine injection by volcanic eruptions: $\mathrm{HCl}$ scavenging and implications for ozone. Science, 260 (1993) 1082-1084.

[112] L. Wallace and W. Livingston, The effect of the Pinatubo cloud on hydrogen chloride and hydrogen fluoride. Geophysical Research Letters, 19 (1992) 209-1211.

[113] G. Mankin, M. T. Coffey and A. Goldman, Airborne observations of $\mathrm{SO}_{2}, \mathrm{HCl}$, and $\mathrm{O}_{3}$ in the stratospheric plume of the Pinatubo volcano in July 1991. Geophysical Research Letters, 19 (1992) 179-182.
[114] S. Solomon, R. W. Sanders, R. R. Garcia and J. G. Keys, Increased chlorine dioxide over Antarctica caused by volcanic aerosols from Mount Pinatubo. Nature, 363 (1993) 245-248.

[115] H. Bureau, H. Keppler and N. Métrich, Volcanic degassing of bromine and iodine: experimental fluid/melt partitioning data and applications to stratospheric chemistry. Earth and Planetary Science Letters, 183 (2000) 51-60.

[116] R. Salawitch, D. Weisenstein, L. Kovalenko, C. Sioris, P. Wennberg, K. Chance, M. Ko and C. McLinden, Sensitivity of Ozone to Bromine in the Lower Stratosphere. Geophysical Research Letters, 32 (2005) L05811.

[117] C. G. Newhall and S. Self, The volcanic explosivity index (VEI) - An estimate of explosive magnitude for historical volcanism. Journal of Geophysical Research, 87 (1982) 1231-1238.

[118] F. Sigmundsson, S. Hreinsdóttir, A. Hooper, T. Árnadóttir, R. Pedersen, M. J. Roberts, N. Óskarsson, A. Auriac, J. Decriem and P. Einarsson, Intrusion triggering of the 2010 Eyjafjallajökull explosive eruption. Nature, 468 (2010) 426-430.

[119]A. Robock, Volcanic eruptions and climate. Reviews of Geophysics, 38 (2000) 191-219.

[120] P. J. Gleckler, T. M. L. Wigley, B. D. Santer, J. M. Gregory, K. AchutaRao and K. E. Taylor, Krakatoa's signature persists in the ocean. Nature, 439 (2006) 675.

[121] J. M. Gregory, J. A. Lowe and S. F. B. Tett, Simulated global-mean sea level changes over the last half-millennium. Journal of Climate, 19 (2006) 4576-4591.

[122] S. O. Rasmussen, M. Bigler, S. P. Blockley, T. Blunier, S. L. Buchardt, H. B. Clausen, I. Cvijanovic, D. Dahl-Jensen, S. J. Johnsen and H. Fischer, A stratigraphic framework for abrupt climatic changes during the Last Glacial period based on three synchronized Greenland ice-core records: refining and extending the INTIMATE event stratigraphy. Quaternary Science Reviews, 106 (2014) 14-28.

[123] W. Dansgaard, H. Clausen, N. Gundestrup, C. Hammer, S. Johnsen, P. Kristinsdottir and N. Reeh, A new Greenland deep ice core. Science, 218 (1982) 1273-1277.

[124] S. J. Johnsen, H. B. Clausen, W. Dansgaard, K. Fuhrer, N. Gundestrup, C. U. Hammer, P. Iversen, J. Jouzel, B. Stauffer and J. P. Steffensen, Irregular glacial interstadials recorded in a new Greenland ice core. Nature 359 (1992) 311-313.

[125] R. B. Alley, D. A. Meese, C. A. Shuman, A. J. Gow, K. C. Taylor, P. M. Grootes, J. W. C. White, M. Ram, E. D. Waddington, P. A. Mayewski, et al., Abrupt increase in Greenland snow accumulation at the end of the Younger Dryas event. Nature 362 (1993) 527-529.

[126] J. P. Steffensen, K. K. Andersen, M. Bigler, H. B. Clausen, D. Dahl-Jensen, H. Fischer, K. Goto-Azuma, M. Hansson, S. J. Johnsen and J. Jouzel, High-resolution Greenland ice core data show abrupt climate change happens in few years. Science, 321 (2008) 680-684.

[127]R. Thomas, E. W. Wolff, R. Mulvaney, S. J. Johnsen, J. P. Steffensen and C. Arrowsmith, Anatomy of a Dansgaard Oeschger warming transition: High - resolution analysis of the North Greenland Ice Core Project ice core. Journal of Geophysical Research: Atmospheres, 114 (2009) D08102. 
[128] L. E. Lisiecki and M. E. Raymo, A Pliocene-Pleistocene stack of 57 globally distributed benthic $\delta^{18} \mathrm{O}$ records. Paleoceanography, 20 (2005) PA1003.

[129] J. R. McConnell, Synchronous volcanic eruptions and abrupt climate change $\sim 17.7$ ka plausibly linked by stratospheric ozone depletion. Proceedings of the National Academy of Sciences of the United States of America, (2017) 10,035-10,040.

[130] Wikipedia, Pliocene (2020) https://en.wikipedia.org/wiki/ Pliocene.

[131] J. D. Hays, J. Imbrie and N. J. Shackleton, Variations in the earth's orbit: Pacemaker of the ice ages. Science, 194 (1976) 1121-1132.

[132] Wikipedia, Milankovitch cycles (2020) https://en.wikipedia.org /wiki/Milankovitch_cycles.

[133] P. Viaggi, $\delta^{18} \mathrm{O}$ and SST signal decomposition and dynamic of the Pliocene-Pleistocene climate system: new insights on orbital nonlinear behavior vs. long-term trend. Progress in Earth and Planetary Science, 5:81 (2018) 37 p.

[134] R. C. Surdam, Geological observations supporting dynamic climatic changes, in Geological $\mathrm{CO}_{2}$ Storage Characterization. (2013), Springer, 1-13.

[135]P. S. Giles, Low-latitude Ordovician to Triassic brachiopod habitat temperatures (BHTs) determined from $\delta^{18} \mathrm{O}$ [brachiopod calcite]: A cold hard look at ice-house tropical oceans. Palaeogeography, Palaeoclimatology, Palaeoecology, 317-318 (2012) 134-152.

[136] Wikipedia, Plate tectonics (2020) https://en.wikipedia.org/ wiki/ Plate_tectonics.

[137] Epica community members, Eight glacial cycles from an
Antarctic ice core. Nature, 429 (2004) 623-628.

[138] H. Cheng, R. L. Edwards, W. S. Broecker, G. H. Denton, X. Kong, Y. Wang, R. Zhang and X. Wang, Ice age terminations. Science, 326 (2009) 248-252.

[139] M. Kennedy, D. Mrofka and C. v. d. Borch, Snowball Earth termination by destabilization of equatorial permafrost methane clathrate. Nature 453 (2008) 642-645.

[140] Wikipedia, Snowball Earth (2020) https://en.wikipedia.org/ wiki/Snowball_Earth.

[141] Environment Canada, Archive of world ozone maps, exp-studies.tor.ec.gc.ca/clf2/e/ozoneworld.html. (2016)

[142] P. L. Ward, Animation of daily northern hemisphere ozone maps 1 January 1991 to 10 May 1991 (2020) www.youtube.com/ watch? $\mathrm{v}=5 \mathrm{y} 1 \mathrm{PU} 2 \mathrm{Qu3ag}$.

[143] D. W. Waugh and L. M. Polvani, Stratospheric polar vortices. The Stratosphere: Dynamics, Transport, and Chemistry, Geophysical Monograph Series 190, (2010) 43-57.

[144] V. Fioletov, Ozone climatology, trends, and substances that control ozone. Atmosphere-Ocean, 46 (2008) 39-67.

[145]R. J. Reed, The role of vertical motion in ozone-weather relationships. Journal of Meteorology, 7 (1950) 263-267.

[146] A. Witze, Rare ozone hole opens over Arctic-and it's big. Nature, 580 (2020) 18-19.

[147] Anonamous, Winter is not coming, https://www.economist. com/graphic-detail/2020/03/28/the-northern-hemispherewinter-of-2019-20-was-the-warmest-ever-on-land. The Economist, March 28th (2020) 77.

[148] NOAA, Teleconnections (2020) https://www.cpc.ncep.noaa. gov/data/teledoc/teleintro.shtml. 